\title{
Effect of Solidification Rate and Rare Earth Metal Addition on the Microstructural Characteristics and Porosity Formation in A356 Alloy
}

\author{
M. G. Mahmoud, ${ }^{1}$ A. M. Samuel, ${ }^{1}$ H. W. Doty, ${ }^{2}$ S. Valtierra, ${ }^{3}$ and F. H. Samuel ${ }^{1}$ \\ ${ }^{1}$ Département des Sciences Appliquées, Université du Québec à Chicoutimi, Chicoutimi, QC, Canada \\ ${ }^{2}$ General Motors Materials Engineering, 823 Joslyn Ave., Pontiac, MI 48340, USA \\ ${ }^{3}$ Nemak, S.A., P.O. Box 100, 66221 Garza Garcia, NL, Mexico \\ Correspondence should be addressed to F. H. Samuel; fhsamuel@uqac.ca
}

Received 1 February 2017; Revised 20 April 2017; Accepted 26 April 2017; Published 24 July 2017

Academic Editor: Francesco Delogu

Copyright ( 2017 M. G. Mahmoud et al. This is an open access article distributed under the Creative Commons Attribution License, which permits unrestricted use, distribution, and reproduction in any medium, provided the original work is properly cited.

\begin{abstract}
The present study was performed on A356 alloy with the main aim of investigating the effects of La and Ce additions to 356 alloys (with and without $100 \mathrm{ppm} \mathrm{Sr}$ ) on the microstructure and porosity formation in these alloys. Measured amounts of La, Ce, and Sr were added to the molten alloy. The results showed that, in the absence of Sr, addition of La and Ce leads to an increase in the nucleation temperature of the $\alpha$-Al dendritic network with a decrease in the temperature of the eutectic Si precipitation, resulting in increasing the freezing range. Addition of $100 \mathrm{ppm}$ Sr results in neutralizing these effects. The presence of La or Ce in the casting has a minor effect on eutectic Si modification, in spite of the observed depression in the eutectic temperature. It should be noted that Ce is more effective than $\mathrm{La}$ as an alternate modifying agent. According to the atomic radius ratio, $r_{\mathrm{La}} / r_{\mathrm{Si}}$ is 1.604 and $r_{\mathrm{Ce}} / r_{\mathrm{Si}}$ is 1.559 , theoretically, which shows that Ce is relatively more effective than La. The present findings confirm that Sr is the most dominating modification agent. Interaction between rare earth (RE) metals and Sr would reduce the effectiveness of Sr. Although modification with $\mathrm{Sr}$ causes the formation of shrinkage porosity, it also reacts with RE-rich intermetallics, resulting in their fragmentation.
\end{abstract}

\section{Introduction}

The main role of rare earth (RE) metals as modifiers is to change the mode of growth of the eutectic silicon. Lanthanum is the most powerful of its kind. Microadditions of RE should be enough to modify the eutectic Si particles provided that a critical cooling rate is reached. RE-treated alloys can maintain the modified structure much longer than Na-treated alloys. A reliable and persistent eutectic modification effect can be obtained with rare earth element addition [1-4]. However, the minimum amount of rare earth elements necessary to obtain proper modification is exceptionally large. Kim and Heine [5] showed that both as-cast grain size and secondary dendrite arm spacing were decreased by adding cerium $(\mathrm{Ce})$ and lanthanum $(\mathrm{La})$ metals.

Aguirre-De la Torre et al. [6] investigated the mechanical properties of A356 aluminum alloy modified with $\mathrm{La} / \mathrm{Ce}$.
It was suggested that an increase in the mechanical performance of the alloy could be achieved by a homogeneous dispersion of fine particles containing $\mathrm{La} / \mathrm{Ce}$ phase. The work of Nogita et al. [7] on eutectic modification of Al-Si alloys with rare earth metals reveals that the impurity induced twinning model of modification, based on atomic radius alone, is inadequate and other mechanisms are essential for the modification process. Furthermore, modification and the eutectic nucleation and growth modes are controlled independently of each other.

Kinetic nucleation of primary $\alpha$-Al dendrites in $\mathrm{Al}-7 \%$ $\mathrm{Si}-\mathrm{Mg}$ cast alloys with $\mathrm{Ce}$ and $\mathrm{Sr}$ additions was analyzed by Chen et al. [8]. The results show that the values of activation energy and nucleation are decreased and the nucleation frequency is increased with the addition of $\mathrm{Ce}$ and $\mathrm{Sr}$ to the alloys. The nucleation temperatures of primary $\alpha$-Al dendrites are decreased with the additions of $\mathrm{Ce}$ and $\mathrm{Sr}$. 
TABLE 1: Chemical composition of the base A356 alloy.

\begin{tabular}{ccccccc}
\hline \multirow{2}{*}{ Alloy } & \multicolumn{5}{c}{ Elements (wt.\%) } \\
& $\mathrm{Si}$ & $\mathrm{Cu}$ & $\mathrm{Mg}$ & $\mathrm{Fe}$ & $\mathrm{Zn}$ & $\mathrm{Al}$ \\
\hline $\mathrm{A} 356$ & 7.2 & $<0.20$ & 0.35 & $<0.20$ & $<0.10$ & $\mathrm{Bal}$ \\
\hline
\end{tabular}

An elaborate review was carried out by Alkahtani et al. [9] on the modification mechanism and microstructural characteristics of eutectic Si in Al-Si casting alloys. Although all rare earth elements have some effect on the eutectic silicon as they are within the atomic radii range predicted by models to be effective in producing growth twins in an Al-Si alloy $\left(r / r_{\mathrm{Si}}=1: 65\right)$, however, they only result in a minor refinement of the plate-like silicon morphology.

El Sebaie et al. $[10,11]$ studied the effects of mischmetal (MM), cooling rate, and heat treatment on the eutectic Si particle characteristics of A319.1, A356.2, and A413.1 Al-Si casting alloys. Measurements of the eutectic Si particles revealed that addition of mischmetal led to partial modification, while full modification was achieved with the addition of $\mathrm{Sr}$ in the as-cast condition, at both high and low cooling rates. The interaction between $\mathrm{Sr}$ and mischmetal weakened the effectiveness of Sr as a Si particle-modifying agent. This effect was particularly evident at the low cooling rate.

The present study was undertaken to investigate the combined effect of solidification rate and addition of rare earth metals with or without $\mathrm{Sr}$ on the characteristics of the eutectic Si structure as well as on porosity formation in cast A356 alloy.

\section{Experimental Procedure}

Table 1 lists the chemical composition of the base A356 alloy used in the present study. The as-received ingots were melted using an electrical resistance furnace at $750^{\circ} \mathrm{C}$. The molten metal was degassed using pure, dry argon, injected into the melt by means of a graphite rotary impeller (at a speed of $130 \mathrm{rpm}$ ). Prior to degassing, measured amounts of Sr, La, and $\mathrm{Ce}$ were added. The three elements were introduced into the molten alloy in the form of $\mathrm{Al}-10 \% \mathrm{Sr}, \mathrm{Al}-20 \% \mathrm{La}$, and $\mathrm{Al}-$ $20 \%$ Ce master alloys. At the end of the degassing period, the molten alloy was poured into three different molds which provided different solidification rates:

(1) A graphite mold preheated at $600^{\circ} \mathrm{C}$ used for carrying out thermal analysis for obtaining the solidification curve (see Figure 1(a)) [12]

(2) A variable angle metallic mold $\left(0^{\circ}, 5^{\circ}\right.$, and $\left.15^{\circ}\right)$ heated at $350^{\circ} \mathrm{C}$ (see Figure 1(b))

(3) A step-like metallic mold heated at either $200^{\circ} \mathrm{C}$ or $400^{\circ} \mathrm{C}$ (see Figure $1(\mathrm{c})$ )

(4) Setup for measuring the solidification curves in the variable angle mold (see Figure 1(d))

For each pouring/casting, samplings for chemical analysis were also taken, to determine the exact composition of the melt. Chemical analyses were carried out at General Motors facilities in Warren, MI, and the results are listed in Table 2. Samples for metallography were also sectioned from all castings. These samples were individually mounted in bakelite using a Struers LaboPress-3 machine, subjected to grinding and polishing procedures using a TegraForce- 5 machine, and subsequently polished to a fine finish using $1 \mu \mathrm{m}$ diamond suspension. The polished samples were examined using an Olympus PMG3 optical microscope-Clemex Vision PE image analysis system. The secondary dendrite arm spacing (SDAS) values were measured using the line intercept method shown in Figure 1(e). Table 3 summarizes the measured SDAS values obtained from the examined samples. Phase identification was carried out using an electron probe microanalyzer (EPMA) in conjunction with energy dispersive X-ray (EDX/EDS) analysis and wavelength dispersive spectroscopic (WDS) analysis where required, integrating a combined JEOL JXA-89001 WD/ED microanalyzer operating at $20 \mathrm{KV}$ and $30 \mathrm{nA}$, where the size of the spot examined was $\sim 2 \mu \mathrm{m}$.

\section{Results and Discussion}

3.1. Thermal Analysis. Solidification kinetics of an unmodified and Sr-modified near-eutectic Al-Si alloy were analyzed by Aparicio et al. [13] who found that there are changes in the solidification rate during eutectic nucleation followed by similar solidification rate evolutions during growth, suggesting that this parameter is governed principally by the heat extraction conditions. The work of Hengcheng et al. [14] on the effects of $\mathrm{Sr}$ and solidification rate on eutectic grain structure in an $\mathrm{Al}-13 \mathrm{wt} . \% \mathrm{Si}$ alloy revealed that the characteristic temperature of eutectic nucleation $\left(T_{N}\right)$, the minimum temperature prior to recalescence $\left(T_{M}\right)$, and the growth temperature $\left(T_{G}\right)$ during cooling as determined by quantitative thermal analysis are continuously decreased with increasing Sr content. As mentioned previously, Nogita et al. [15] reported that all rare earth elements had some effect on the eutectic silicon; however, europium was the only element to cause fully modified, fine fibrous silicon, whereas the other elements only produced a minor refinement of the plate-like silicon morphology.

Ferdian et al. [16] studied the effect of cooling rate on the eutectic modification in A356 alloy. Figure 2 shows the parameters taken from thermal analysis cooling curves for characterizing the (Al)-Si eutectic arrest which, according to the authors, comprises the minimum eutectic temperature $\left(T_{e, \min }\right)$, maximum eutectic temperature $\left(T_{e, \max }\right)$, and recalescence $\left(\Delta T_{e}\right)$. In case of no recalescence, $T_{e, \max }$ was obtained as the temperature for which the absolute value of the cooling rate (time derivative of the cooling curve) was the highest. $\Delta T_{d}=T_{R}-T_{e, \max }$ is the eutectic depression, where $T_{R}$ is the equilibrium eutectic temperature calculated using (1) which was obtained by updating the equation proposed by Mondolfo [17].

$$
\begin{aligned}
& T_{R}\left({ }^{\circ} \mathrm{C}\right)=577-\frac{12.5}{w_{\mathrm{Si}}} \cdot\left(4.59 \cdot w_{\mathrm{Mg}}+1.37 \cdot w_{\mathrm{Fe}}\right. \\
& \left.\quad+1.65 \cdot w_{\mathrm{Cu}}+0.35 \cdot w_{\mathrm{Zn}}+2.54 \cdot w_{\mathrm{Mn}}+3.52 \cdot w_{\mathrm{Ni}}\right) .
\end{aligned}
$$

Applying this equation for the present alloy shows that $T_{R}$ for A356.1 alloy is about $570.8^{\circ} \mathrm{C}$. 
TABLE 2

(a) Modifier additions and corresponding A356 alloy codes, graphite mold castings

\begin{tabular}{|c|c|c|c|c|c|c|c|c|c|}
\hline \multirow{3}{*}{ Alloy } & \multirow{3}{*}{ Mold type } & \multirow{3}{*}{ Mold temp. $\left({ }^{\circ} \mathrm{C}\right)$} & \multirow{3}{*}{ Alloy code } & \multicolumn{6}{|c|}{ Modifier addition (wt.\%) } \\
\hline & & & & \multicolumn{3}{|c|}{ Aimed } & \multicolumn{3}{|c|}{ Actual } \\
\hline & & & & $\mathrm{Sr}$ & $\mathrm{La}$ & $\mathrm{Ce}$ & $\mathrm{Sr}$ & $\mathrm{La}$ & $\mathrm{Ce}$ \\
\hline \multirow{23}{*}{ A356 } & \multirow{23}{*}{ Graphite } & \multirow{23}{*}{600} & $\mathrm{~TB}$ & 0 & 0 & 0 & 0 & 0 & 0 \\
\hline & & & $\mathrm{T} 10$ & 0 & 0.2 & 0 & 0 & 0.165 & 0 \\
\hline & & & $\mathrm{T} 1$ & 0 & 0.5 & 0 & 0 & 0.356 & 0 \\
\hline & & & $\mathrm{T} 2$ & 0 & 1 & 0 & 0 & 0.685 & 0 \\
\hline & & & T3 & 0 & 1.5 & 0 & 0 & 1.025 & 0 \\
\hline & & & T11 & 0 & 0 & 0.2 & 0 & 0.002 & 0.082 \\
\hline & & & $\mathrm{T} 4$ & 0 & 0 & 0.5 & 0 & 0.006 & 0.185 \\
\hline & & & T5 & 0 & 0 & 1 & 0 & 0.006 & 0.317 \\
\hline & & & T6 & 0 & 0 & 1.5 & 0 & 0.009 & 1.088 \\
\hline & & & $\mathrm{T} 7$ & 0 & 0.5 & 0.5 & 0 & 0.442 & 0.282 \\
\hline & & & T8 & 0 & 1 & 1 & 0 & 0.781 & 0.377 \\
\hline & & & T9 & 0 & 1.5 & 1.5 & 0 & 1.073 & 0.531 \\
\hline & & & T10S & 0.01 & 0.2 & 0 & 0.0079 & 0.165 & 0 \\
\hline & & & $\mathrm{T} 1 \mathrm{~S}$ & 0.01 & 0.5 & 0 & 0.0109 & 0.356 & 0 \\
\hline & & & $\mathrm{T} 2 \mathrm{~S}$ & 0.01 & 1 & 0 & 0.0077 & 0.685 & 0 \\
\hline & & & T3S & 0.01 & 1.5 & 0 & 0.0077 & 1.025 & 0 \\
\hline & & & T11S & 0.01 & 0 & 0.2 & 0.0073 & 0.002 & 0.182 \\
\hline & & & T4S & 0.01 & 0 & 0.5 & 0.0078 & 0.006 & 0.358 \\
\hline & & & T5S & 0.01 & 0 & 1 & 0.0081 & 0.006 & 0.817 \\
\hline & & & T6S & 0.01 & 0 & 1.5 & 0.0081 & 0.009 & 1.288 \\
\hline & & & T7S & 0.01 & 0.5 & 0.5 & 0.0083 & 0.442 & 0.382 \\
\hline & & & T8S & 0.01 & 1 & 1 & 0.0083 & 0.781 & 0.877 \\
\hline & & & T9S & 0.01 & 1.5 & 1.5 & 0.0089 & 1.073 & 1.231 \\
\hline
\end{tabular}

(b) Actual Sr concentrations obtained for the step-like and variable angle mold castings of A356 alloy

\begin{tabular}{|c|c|c|}
\hline Mold & Alloy code & $\mathrm{Sr}(\mathrm{ppm})^{*}$ \\
\hline \multirow{10}{*}{ Step-likemold } & S12 & 83 \\
\hline & S22 & 95 \\
\hline & S32 & 84 \\
\hline & $\mathrm{S} 42$ & 105 \\
\hline & S52 & 108 \\
\hline & S14 & 79 \\
\hline & S24 & 73 \\
\hline & S34 & 77 \\
\hline & $\mathrm{S} 44$ & 88 \\
\hline & S54 & 89 \\
\hline \multirow{12}{*}{ Variable angle mold } & DBLS & 127 \\
\hline & D10LS & 79 \\
\hline & D1LS & 109 \\
\hline & D2LS & 74 \\
\hline & D3LS & 74 \\
\hline & D11LS & 73 \\
\hline & D4LS & 70 \\
\hline & D5LS & 71 \\
\hline & D6LS & 77 \\
\hline & D7LS & 75 \\
\hline & D8LS & 78 \\
\hline & D9LS & 70 \\
\hline
\end{tabular}

${ }^{*}$ Aimed amount was $100 \mathrm{ppm} \pm 20 \mathrm{ppm}$. 


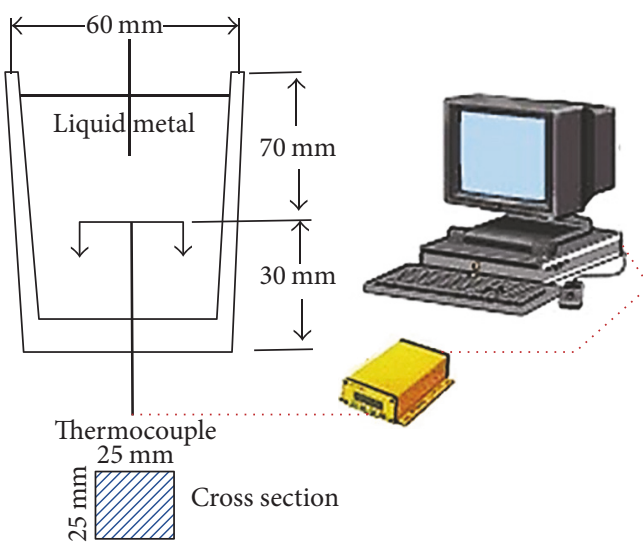

(a) Setup showing the graphite mold used for carrying out thermal analysis
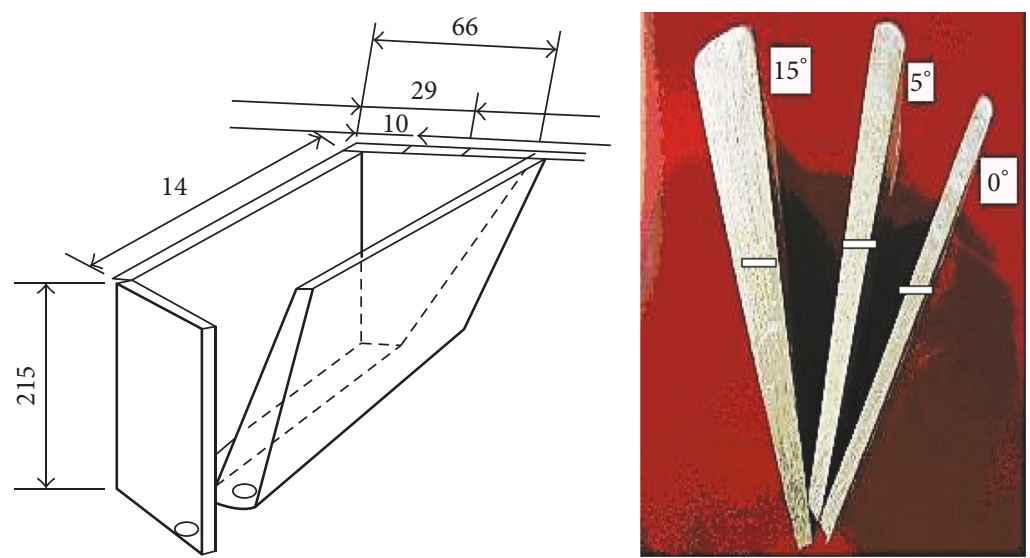

(b) (L) Variable angle metallic mold (dimensions are in $\mathrm{mm}$ ) and (R) obtained castings; the white blocks indicate the sampling positions almost halfway along the casting height

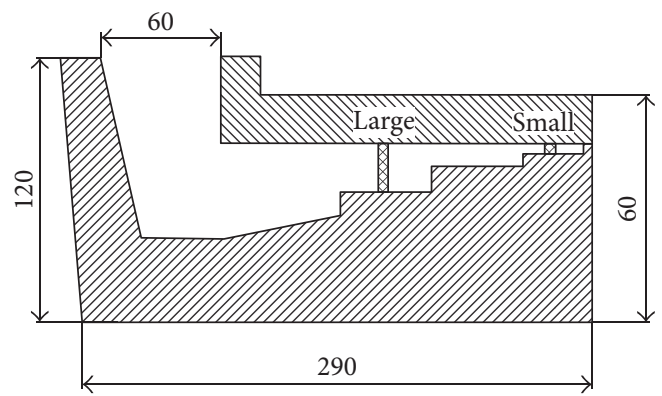

(c) (L) Step-like metallic mold (dimensions are in $\mathrm{mm}$ ) and (R) the obtained casting

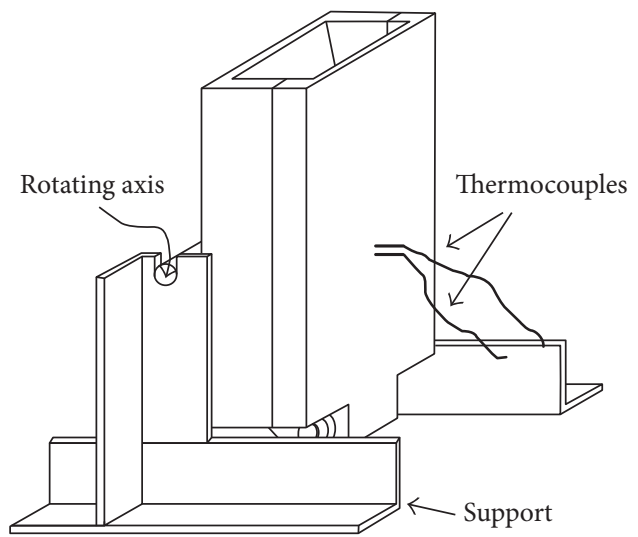

(d) Setup showing the variable angle mold used for carrying out thermal analysis

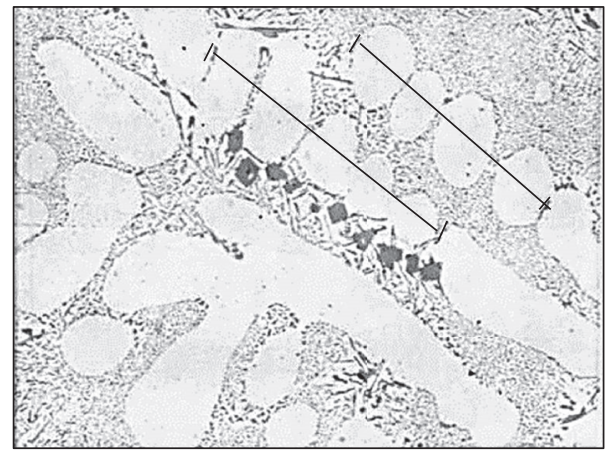

(e) Intercept method used to measure the secondary dendrite arm spacing

Figure 1

Figure 3(a) presents the solidification curve and its first derivative obtained from the base A356 alloy using the preheated graphite mold while Figure 3(b) shows the effect of $100 \mathrm{ppm} \mathrm{Sr}$ addition to the base alloy. It is inferred from Figure 3 that addition of Sr resulted in increasing the nucleation temperature of $\alpha$ - $\mathrm{Al}$ from about $614.4^{\circ} \mathrm{C}$ to $616.4^{\circ} \mathrm{C}$, that is, $2^{\circ} \mathrm{C}$, with a decrease in the eutectic temperature from $569.65^{\circ} \mathrm{C}$ to $562.23^{\circ} \mathrm{C}$ (approximately $7.4^{\circ} \mathrm{C}$ ) with a total increase in the freezing zone by about $9.5^{\circ} \mathrm{C}$. Modification with Sr also resulted in the merging of peaks (3) and (4) observed in Figure 3(a). The studies carried out by Samuel et al. $[18,19]$ revealed that $\mathrm{Sr}$ addition causes fragmentation of the $\pi$-iron phase during the course of solidification which explains the disappearance of peak (2) seen in Figure 3(b). Due to the directional solidification nature of castings made using the variable angle mold (Figure 3(c)), it is difficult 


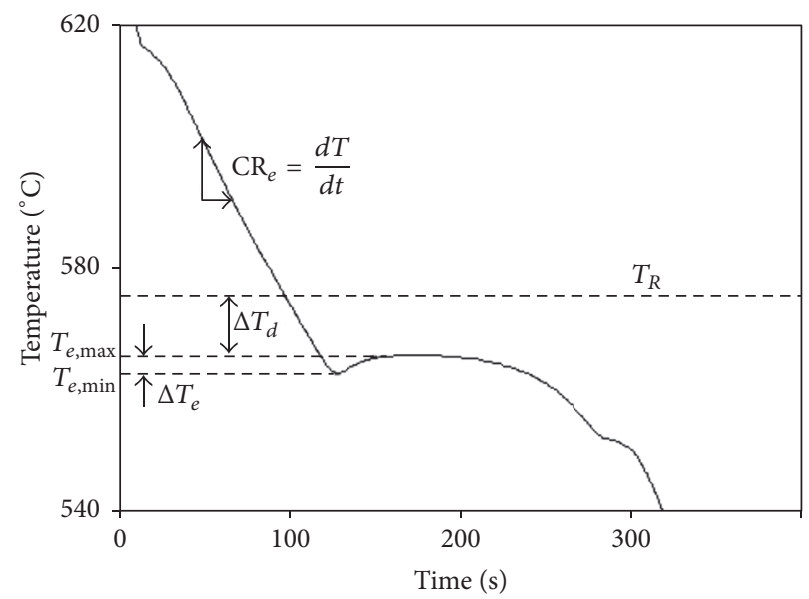

FIGURE 2: Solidification parameters of 356 alloy [16].

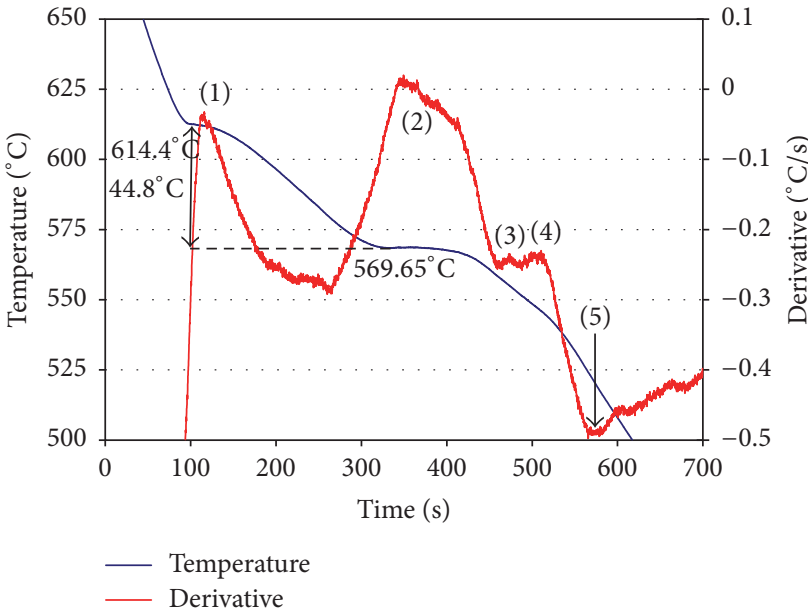

(a) Temperature-time curve and first derivative of the A356 base alloy showing (1) precipitation of $\alpha$-Al dendrite network, (2) Al-Si eutectic reaction, (3) transformation of $\beta$-Fe to $\pi$-Fe phase, (4) precipitation of $\mathrm{Mg}_{2} \mathrm{Si}$, and (5) end of solidification [31]

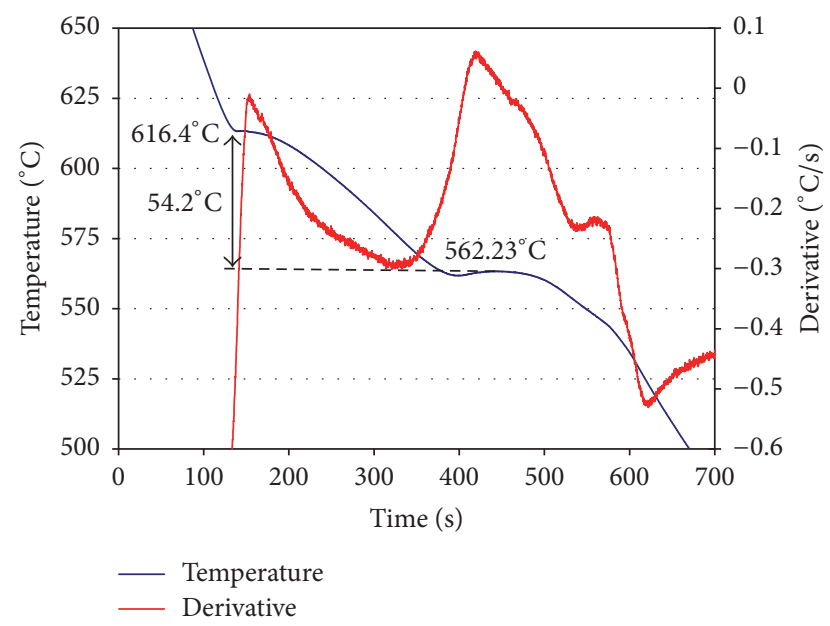

(b) Temperature-time curve and its first derivative obtained from the A356 alloy modified with about $100 \mathrm{ppm} \mathrm{Sr}$

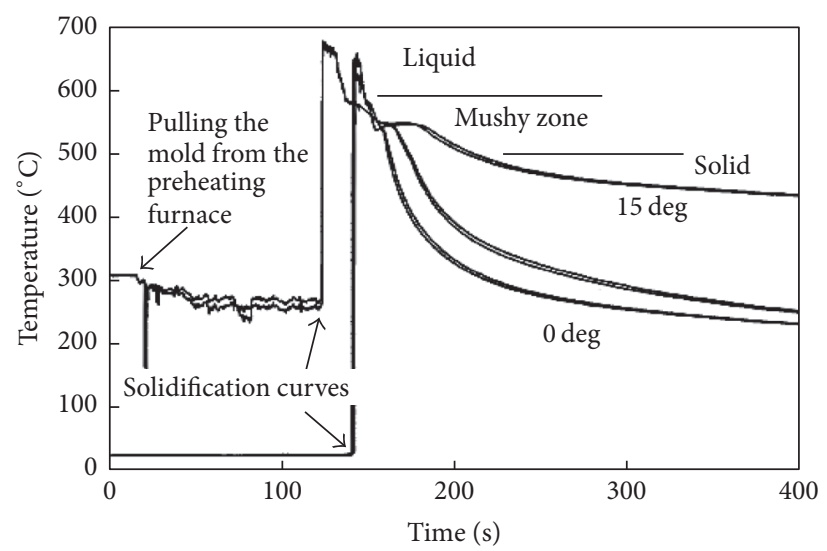

(c) Temperature-time curves obtained from the variable angle mold at different angles

FiguRe 3 
TABLE 3: Average secondary dendrite arm spacing of the examined A356 alloy samples.

\begin{tabular}{|c|c|c|c|c|}
\hline \multirow{2}{*}{ Mold } & \multirow{2}{*}{ Mold temp. $\left({ }^{\circ} \mathrm{C}\right)$} & \multirow{2}{*}{ Mold section } & \multicolumn{2}{|c|}{ SDAS $^{*}(\mu \mathrm{m})$} \\
\hline & & & Average & $\mathrm{SD}$ \\
\hline Graphite & 600 & Center & 68.63 & 5.49 \\
\hline \multirow{4}{*}{ Step-like } & 200 & Large & 31.56 & 2.92 \\
\hline & 200 & Small & 16.17 & 1.89 \\
\hline & 400 & Large & 41.66 & 3.02 \\
\hline & 400 & Small & 22.46 & 3.96 \\
\hline \multirow{2}{*}{ Variable angle } & 325 & Large & 53.62 & 5.7 \\
\hline & 325 & Small & 25.04 & 3.0 \\
\hline
\end{tabular}

${ }^{*}$ Secondary dendrite arm spacing obtained over 20 measurements per sample. SD: standard deviation.
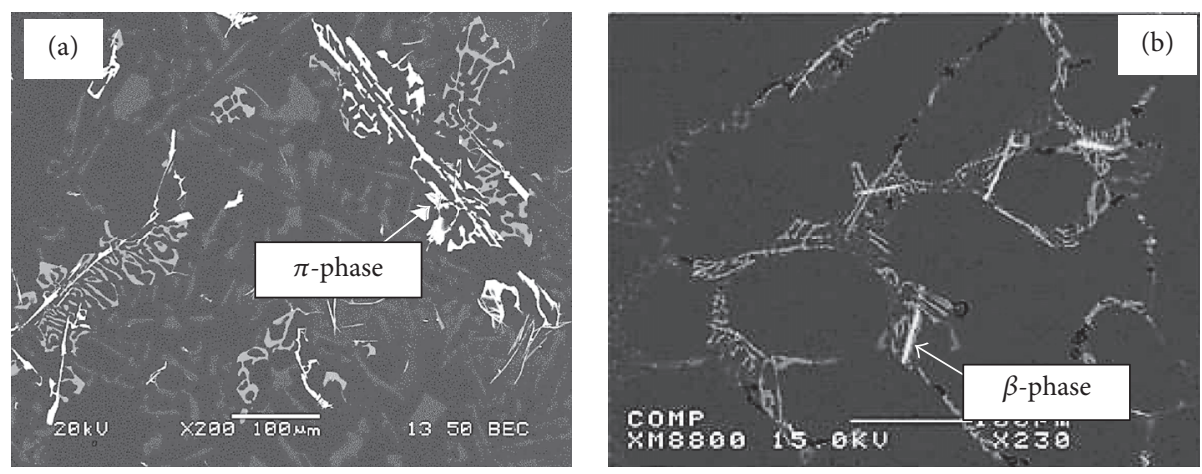

FIGURE 4: Backscattered electron images of A356 alloy in the as-cast condition: (a) nonmodified and (b) modified with 100 ppm Sr, showing $\pi$-phase and $\beta$-phase particles.
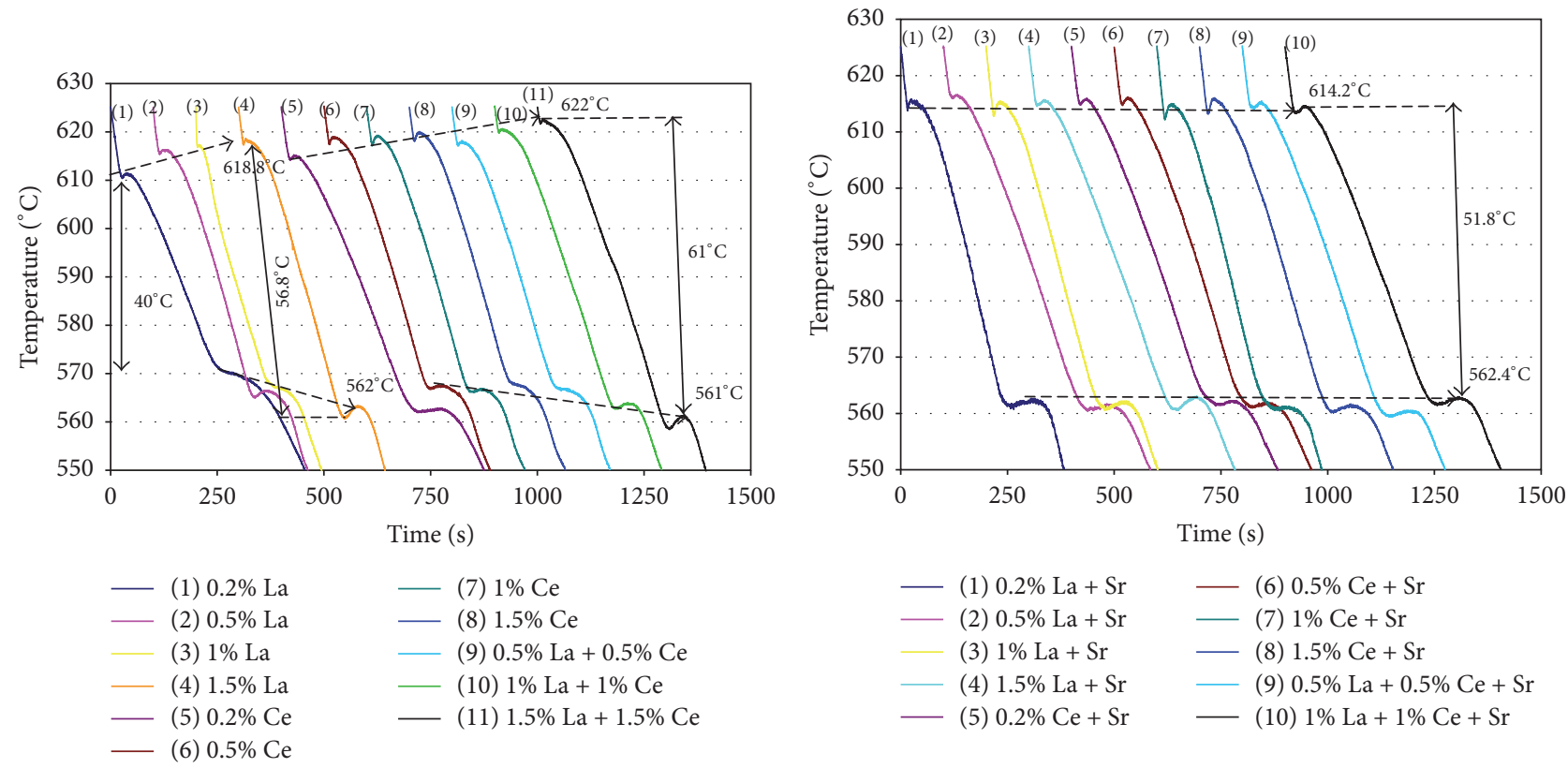

- (7) $1 \% \mathrm{Ce}$

- (8) $1.5 \% \mathrm{Ce}$

(9) $0.5 \% \mathrm{La}+0.5 \% \mathrm{Ce}$

(10) $1 \% \mathrm{La}+1 \% \mathrm{Ce}$

- (11) $1.5 \% \mathrm{La}+1.5 \% \mathrm{Ce}$

(a) Solidification curves obtained from A356 alloys containing different La and Ce additions (no Sr was added). The black arrow indicates the start of solidification $[18,19]$ 


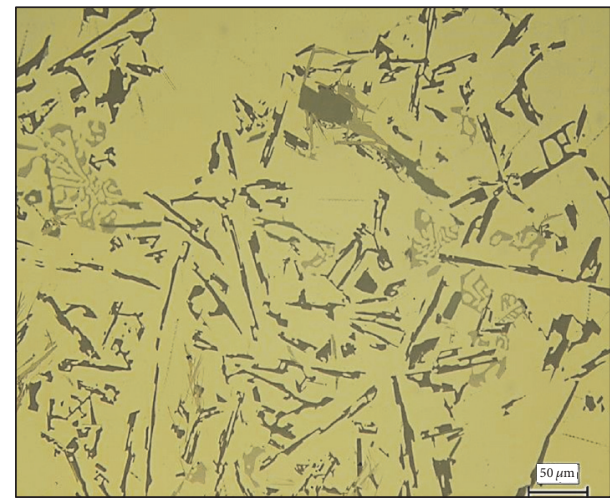

(a)

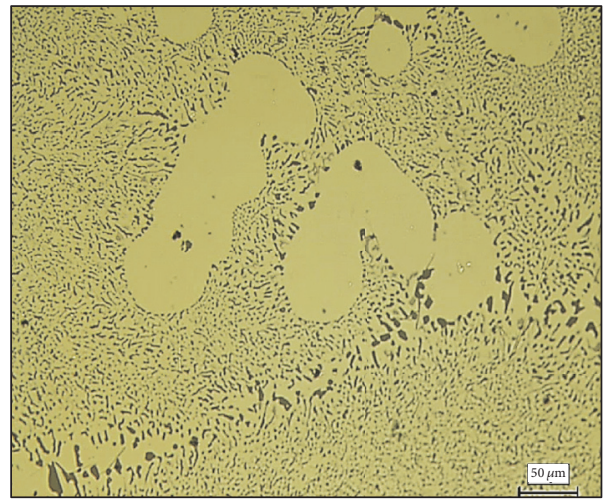

(c)

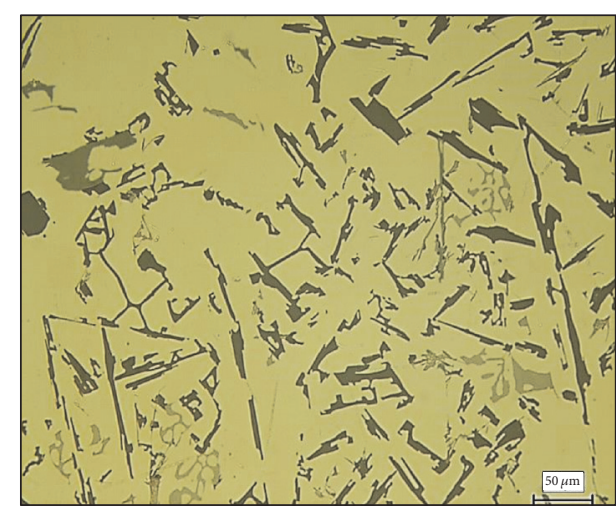

(b)

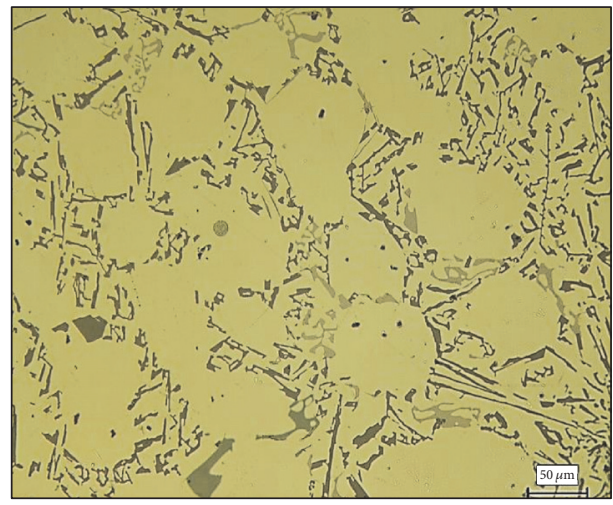

(d)

FIGURE 6: Variation in the eutectic Si morphology as a function of melt treatment: (a) no addition, (b) addition of 3\% RE (alloy \#11 in Figure 4(a)), (c) modification with $100 \mathrm{ppm} \mathrm{Sr}$, and (d) addition of 2\% RE to Sr-modified alloy (alloy \#10 in Figure 4(b)).

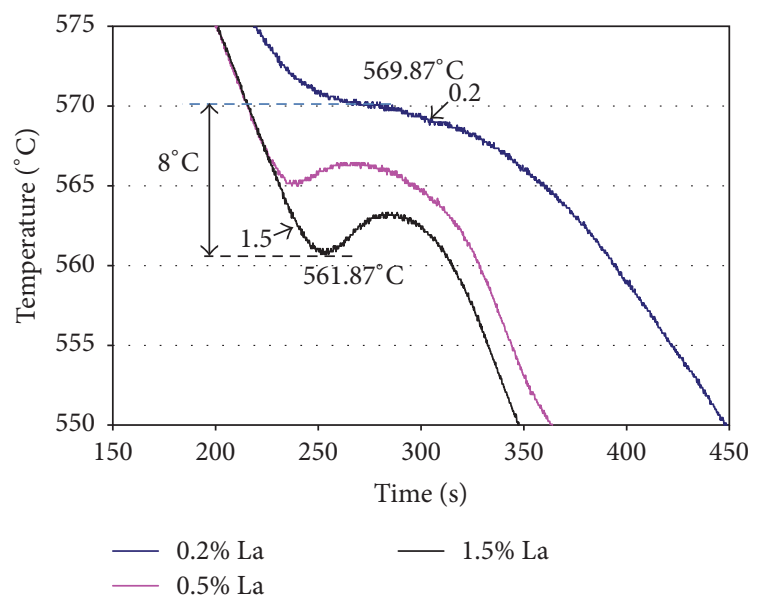

(a) Effect of La addition on the depression in the eutectic temperature in non-Sr-modified A356 alloys

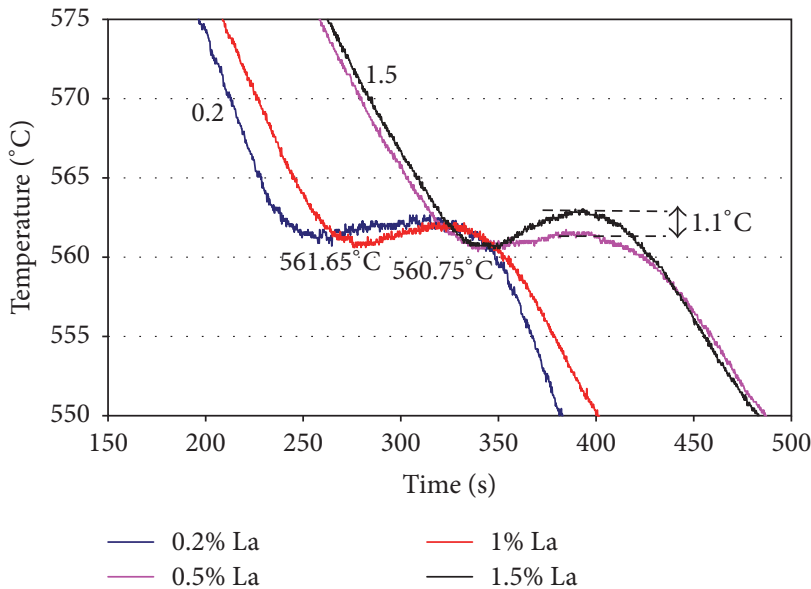

(b) Effect of La addition on the depression in the eutectic temperature in non-Sr-modified A356 alloys 


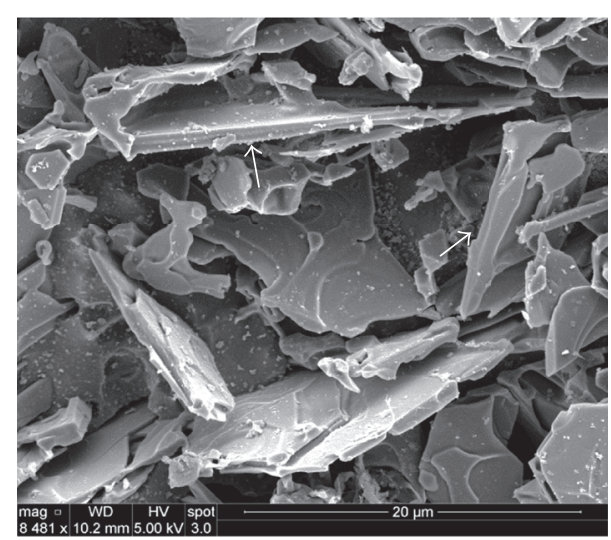

(a)

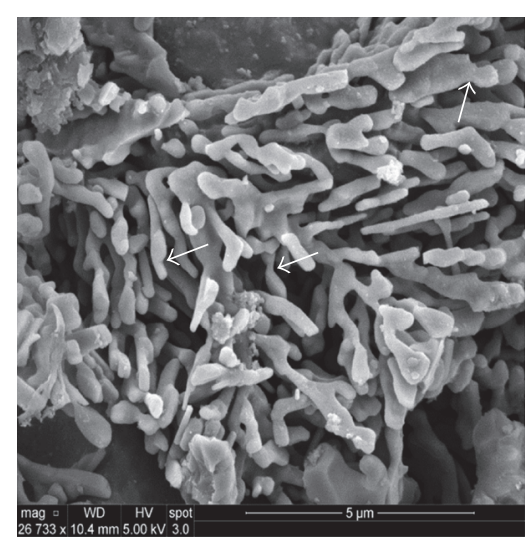

(b)

FIGURE 8: Eutectic Si morphology revealed in deep etched samples of (a) base alloy without Sr and (b) base alloy + Sr.

to identify the sequence of reactions taking place during solidification. Thus, in this case, the values of SDAS are based on the polished samples. Figure 4 illustrates the effect of the Sr modification on the microstructure of the A356 alloy.

Figure 5(a) illustrates the changes in the characteristics of the temperature-time curves as a function of the added amount of $\mathrm{La}$ and Ce. In Figure 5(a), addition of 1\% La resulted in increasing the freezing zone from $44.8^{\circ} \mathrm{C}$ (Figure 3(a)) to $56.8^{\circ} \mathrm{C}$, with a further increase to $61^{\circ} \mathrm{C}$ and $623^{\circ} \mathrm{C}$ with the use of $1.5 \% \mathrm{La}+1.5 \% \mathrm{Ce}$ (see Table $2(\mathrm{a})$ for actual concentrations). This behavior depends on the added element, that is, La or Ce. The reported increase in the freezing zone is brought about by the increase in the nucleation temperature of $\alpha$-Al coupled with the depression in the eutectic temperature. The increase in the freezing zone is expected to result in poor feedability of the alloy and hence more porosity $[20,21]$. It should be noted that $\mathrm{La}$ is more effective than Ce in increasing the freezing zone. It should be emphasized here that the addition of the RE elements changes the nucleation process of the molten alloy and, hence, the undercooling of the melt will be influenced. Modifying the alloys with about $100 \mathrm{ppm} \mathrm{Sr}$ resulted in neutralizing the effect of RE on the change in both $\alpha$-Al and eutectic precipitation temperatures, as shown in Figure 5(b), which is very close to that presented in Figure 3(b). In this case, the solidification temperature range is about $53^{\circ} \mathrm{C}$. Reis et al. [20] presented a model for prediction of shrinkage defects in long and short freezing range materials. Their results showed that internal and external shrinkage defects depend on the freezing range of the metal. A short freezing range results mainly in internal shrinkage whereas the long freezing range shows more external shrinkage. Figure 6 presents the microstructure of the eutectic Si when the alloy was subjected to different melt treatments. It is evident from Figure 6(b) that addition of 3\% RE to the base alloy has no significant modification effect in spite of the observed decrease in the eutectic temperature. Thus, in this case, the observed depression in the eutectic temperature should not be used as an indicator of modification [11]. When the base alloy is treated with $100 \mathrm{ppm} \mathrm{Sr}$ (Figure 6(c)), the microstructure is fully modified. Due to RE-Sr interaction, the Si particles tend to lose their fibrous morphology; that is, they are partially modified (Figure 6(d)). These observations will be discussed in more detail in the next section.

The depression of the eutectic temperature is the feature that is used most often in thermal analysis as an indicator of modification [22]. As eutectic temperature is easy to measure, it is generally employed to assess whether or not a melt is properly modified. However, if temperature alone is used as the criterion for proper modification, it is difficult to detect overmodified structures, because the greatest change of temperature occurs in the unmodified-to-modified transition [23]. Figure 7(a) exhibits the depression in the eutectic temperature with the addition of $\mathrm{La}$ in the absence of $\mathrm{Sr}$. In this case, addition of $1.5 \%$ La resulted in decreasing the eutectic temperature by about $8^{\circ} \mathrm{C}$. Modification of the same alloys with $100 \mathrm{ppm}$ Sr neutralized this effect, as seen from Figure 7(b). Thus, the depression in the eutectic temperature is mainly due to $\mathrm{Sr}$ modification $\left(6^{\circ} \mathrm{C}\right)$ with undercooling of about $2^{\circ} \mathrm{C}$. It should be mentioned here that the addition of $0.2 \%$ RE has no noticeable effect on the eutectic temperature.

\subsection{Eutectic Si Particle Characteristics}

3.2.1. Variable Angle Mold. Figure 8(a) shows the morphology of the eutectic Si in deep etched samples of A356 alloy. In the case of the nonmodified alloy sample, the $\mathrm{Si}$ appears in the form of platelets with sharp edges (arrow). Addition of $80 \mathrm{ppm} \mathrm{Sr}$ (Figure 8(b)) resulted in changing the Si morphology into an interconnected "branched tree" type, with the particles exhibiting necking (arrow). Table 4 lists the eutectic Si particle characteristics measured from the variable angle mold at two tilting angles, that is, 0 and 15 degrees. At zero tilting angle (SDAS $\sim 25 \mu \mathrm{m}$ ), the Si particles were refined due to the high solidification rate, as documented in Table 4(a). It is evident that the addition of RE up to 3\% has no significant refining effect. Also, the standard deviation is noticeably large, indicating a marked variation in the $\mathrm{Si}$ particle size. Increasing the mold tilting angle to 15 degrees, thereby reducing the solidification rate (SDAS $\sim 52 \mu \mathrm{m}$ ), the 


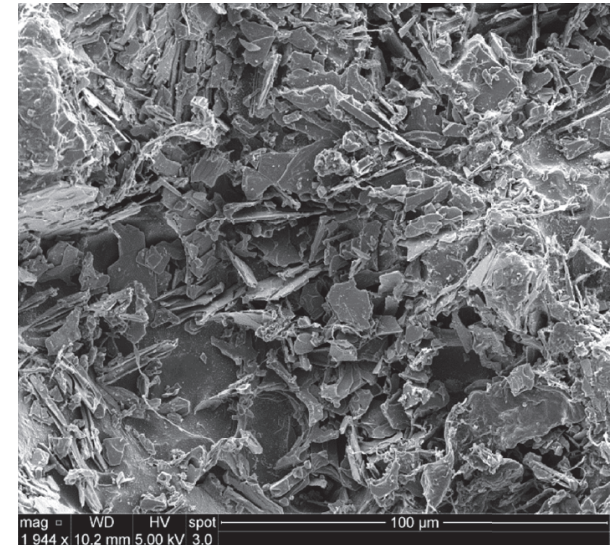

(a) Nonmodified alloy, DBL alloy

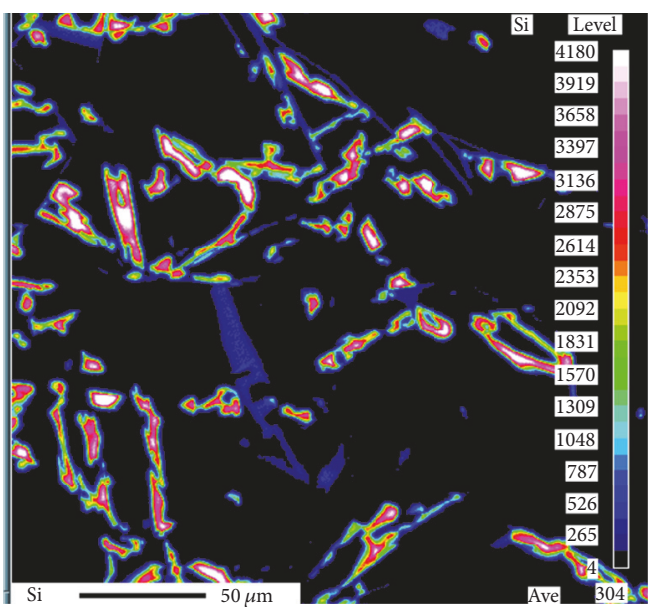

(c) D7L alloy

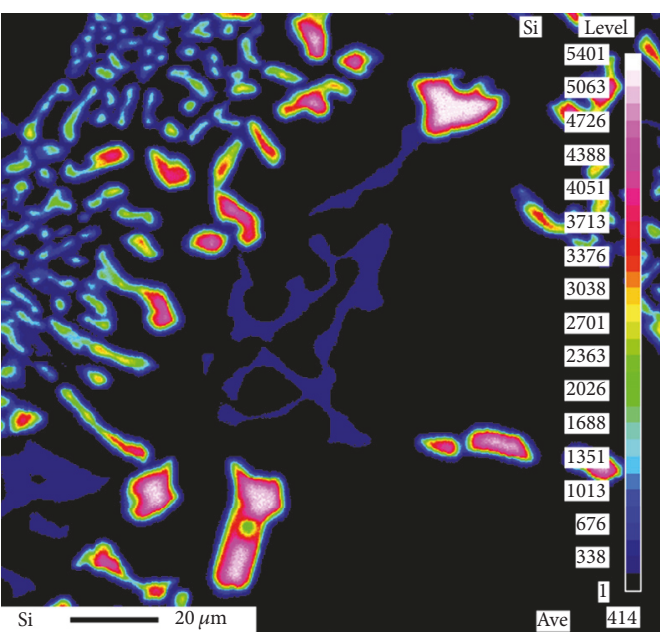

(e) D7LS alloy

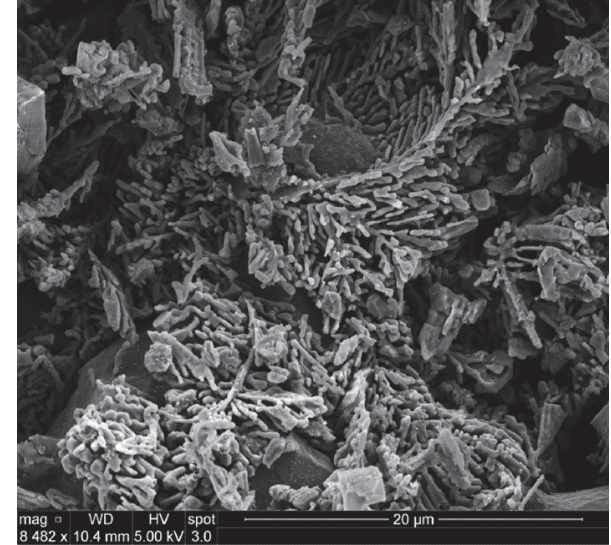

(b) After Sr addition, DBLS alloy

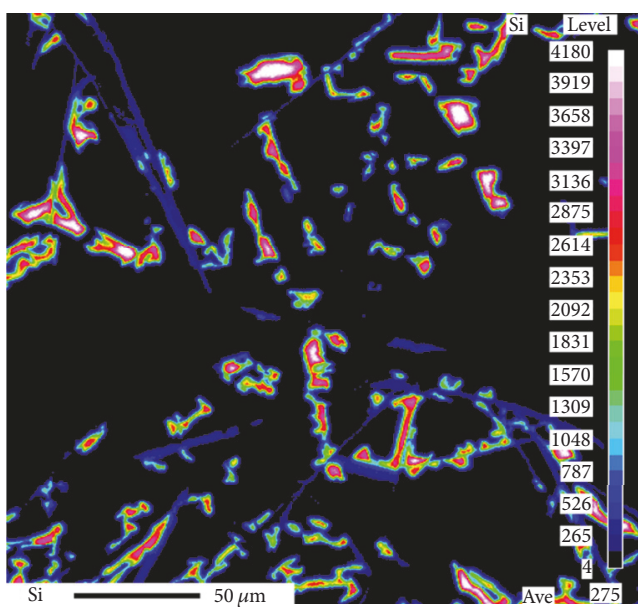

(d) D9L alloy

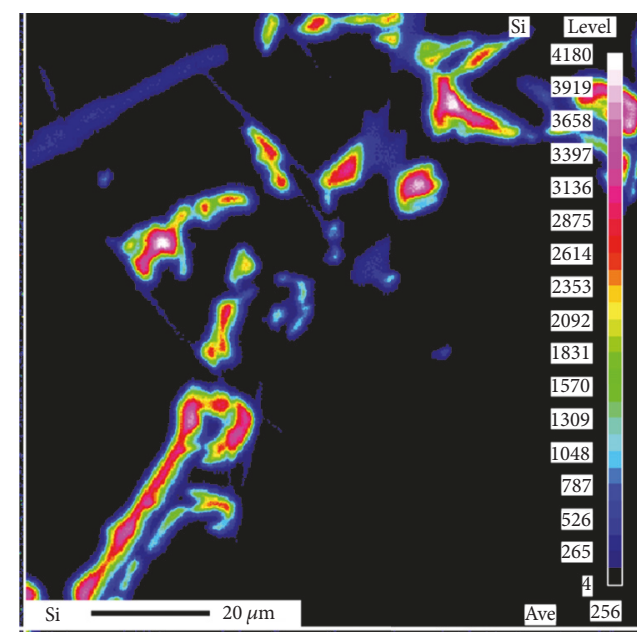

(f) D9LS alloy

FIGURE 9: Examples of the eutectic Si particle size and distribution after different melt treatments/additions in A356 alloy samples obtained from the variable angle mold (large) castings. 
TABLE 4

(a) Eutectic Si particle characteristics observed in variable angle mold (small* ) samples of A356 alloys containing La and Ce additions

\begin{tabular}{|c|c|c|c|c|c|c|c|c|}
\hline \multirow{3}{*}{ Alloy code } & \multirow{2}{*}{\multicolumn{2}{|c|}{ RE content }} & \multicolumn{6}{|c|}{ Silicon particle characteristics } \\
\hline & & & \multicolumn{2}{|c|}{ Area $\left(\mu \mathrm{m}^{2}\right)$} & \multicolumn{2}{|c|}{ Length $(\mu \mathrm{m})$} & \multirow{2}{*}{ Aspect ratio } & \multirow{2}{*}{ Density (number $/ \mathrm{mm}^{2}$ ) } \\
\hline & $\mathrm{La}($ wt.\%) & $\mathrm{Ce}($ wt.\%) & Average & SD & Average & SD & & \\
\hline DBS & 0 & 0 & 5.990 & 7.032 & 5.957 & 7.421 & 2.671 & 8240 \\
\hline D10S & 0.165 & 0 & 8.805 & 10.020 & 8.536 & 10.30 & 2.468 & 6037 \\
\hline D1S & 0.356 & 0 & 6.492 & 6.958 & 6.459 & 11.70 & 2.282 & 8174 \\
\hline $\mathrm{D} 2 \mathrm{~S}$ & 0.685 & 0 & 7.08 & 8.56 & 5.409 & 6.78 & 2.288 & 4201 \\
\hline D3S & 1.025 & 0 & 3.211 & 5.164 & 3.101 & 5.82 & 2.221 & 10149 \\
\hline D11S & 0.032 & 0.082 & 7.154 & 7.915 & 6.870 & 9.75 & 2.553 & 6307 \\
\hline $\mathrm{D} 4 \mathrm{~S}$ & 0.136 & 0.185 & 6.413 & 7.472 & 6.307 & 8.53 & 2.533 & 7330 \\
\hline D5S & 0.046 & 0.317 & 5.683 & 6.376 & 4.967 & 6.37 & 2.451 & 7902 \\
\hline D6S & 0.089 & 1.088 & 8.105 & 9.673 & 6.094 & 9.01 & 2.367 & 6795 \\
\hline D7S & 0.44 & 0.282 & 5.058 & 5.868 & 6.820 & 10.80 & 2.219 & 8331 \\
\hline D8S & 0.781 & 0.877 & 5.917 & 6.754 & 7.555 & 9.96 & 2.355 & 6253 \\
\hline D9S & 1.073 & 0.831 & 4.426 & 4.914 & 5.254 & 7.60 & 2.124 & 16277 \\
\hline
\end{tabular}

Note. Mold temperature: $325^{\circ} \mathrm{C} ;{ }^{*}$ small: angle of variable angle mold is $0^{\circ}$.

(b) Eutectic Si particle characteristics observed in variable angle mold (large $\left.{ }^{*}\right)$ samples of A356 alloys containing La and Ce additions

\begin{tabular}{|c|c|c|c|c|c|c|c|c|}
\hline \multirow{3}{*}{ Alloy code } & \multirow{2}{*}{\multicolumn{2}{|c|}{$\begin{array}{c}\text { RE addition } \\
\text { Actual }\end{array}$}} & \multicolumn{6}{|c|}{ Silicon particle characteristics } \\
\hline & & & \multicolumn{2}{|c|}{ Area $\left(\mu \mathrm{m}^{2}\right)$} & \multicolumn{2}{|c|}{ Length $(\mu \mathrm{m})$} & \multirow{2}{*}{ Aspect ratio } & \multirow{2}{*}{ Density (number $/ \mathrm{mm}^{2}$ ) } \\
\hline & $\mathrm{La}($ wt.\%) & $\mathrm{Ce}$ (wt.\%) & Average & SD & Average & $\mathrm{SD}$ & & \\
\hline $\mathrm{DBL}$ & 0 & 0 & 21.45 & 29.53 & 9.467 & 9.397 & 2.586 & 35521 \\
\hline D10L & 0.165 & 0 & 28.48 & 36.16 & 19.38 & 10.230 & 2.275 & 2349 \\
\hline D1L & 0.356 & 0 & 18.24 & 28.87 & 11.42 & 9.498 & 2.237 & 5521 \\
\hline $\mathrm{D} 2 \mathrm{~L}$ & 0.685 & 0 & 24.43 & 37.46 & 15.3 & 10.95 & 2.287 & 3754 \\
\hline D3L & 1.025 & 0 & 19.59 & 13.96 & 9.374 & 5.804 & 2.195 & 9446 \\
\hline D11L & 0.032 & 0.082 & 16.37 & 23.23 & 12.42 & 8.741 & 2.600 & 7352 \\
\hline $\mathrm{D} 4 \mathrm{~L}$ & 0.136 & 0.185 & 16.19 & 25.41 & 10.23 & 8.960 & 2.499 & 5924 \\
\hline D5L & 0.046 & 0.317 & 16.09 & 28.03 & 8.752 & 9.570 & 2.367 & 5668 \\
\hline D6L & 0.089 & 1.088 & 18.66 & 31.05 & 9.310 & 10.410 & 2.305 & 5236 \\
\hline D7L & 0.44 & 0.282 & 11.93 & 18.95 & 12.01 & 7.605 & 2.343 & 7515 \\
\hline D8L & 0.781 & 0.877 & 15.95 & 24.51 & 13.200 & 8.162 & 2.332 & 4122 \\
\hline D9L & 1.073 & 0.831 & 8.20 & 12.82 & 5.880 & 5.416 & 2.185 & 12862 \\
\hline
\end{tabular}

Note. Mold temperature: $325^{\circ} \mathrm{C}$; ${ }^{*}$ large: angle of variable angle mold is $15^{\circ}$.

(c) Characteristics of eutectic Si particles in variable angle mold (large* ) samples of Sr-modified A356 alloys containing La and Ce additions

\begin{tabular}{|c|c|c|c|c|c|c|c|c|c|}
\hline \multirow{3}{*}{ Alloy code } & \multirow{2}{*}{\multicolumn{3}{|c|}{$\begin{array}{c}\text { Addition } \\
\text { Actual }\end{array}$}} & \multicolumn{6}{|c|}{ Silicon particle characteristics } \\
\hline & & & & \multicolumn{2}{|c|}{ Area $\left(\mu \mathrm{m}^{2}\right)$} & \multicolumn{2}{|c|}{ Length $(\mu \mathrm{m})$} & \multirow{2}{*}{ Aspect ratio } & \multirow{2}{*}{ Density (number $/ \mathrm{mm}^{2}$ ) } \\
\hline & $\mathrm{Sr}(\mathrm{ppm})$ & $\mathrm{La}($ wt.\%) & $\mathrm{Ce}($ wt.\%) & Average & SD & Average & SD & & \\
\hline DBLS & 127 & 0 & 0 & 1.765 & 3.906 & 2.161 & 2.431 & 2.061 & 64199 \\
\hline D10LS & 69 & 0.165 & 0 & 2.138 & 3.930 & 2.345 & 2.378 & 1.952 & 58454 \\
\hline D1LS & 109 & 0.356 & 0 & 2.385 & 5.157 & 2.494 & 2.958 & 1.974 & 42526 \\
\hline D2LS & 74 & 0.685 & 0 & 4.240 & 2.470 & 2.625 & 8.348 & 2.370 & 5374 \\
\hline D3LS & 74 & 1.025 & 0 & 5.775 & 2.633 & 3.815 & 4.688 & 2.262 & 18163 \\
\hline D11LS & 73 & 0.033 & 0.082 & 3.549 & 6.440 & 3.207 & 3.862 & 2.114 & 38504 \\
\hline D4LS & 70 & 0.136 & 0.185 & 1.876 & 3.542 & 2.165 & 2.053 & 1.937 & 55283 \\
\hline D5LS & 71 & 0.046 & 0.317 & 2.524 & 4.593 & 2.565 & 2.854 & 1.906 & 49097 \\
\hline D6LS & 77 & 0.089 & 1.088 & 1.885 & 4.197 & 2.155 & 2.435 & 1.927 & 61875 \\
\hline D7LS & 75 & 0.44 & 0.282 & 3.119 & 5.461 & 2.931 & 3.235 & 1.927 & 36082 \\
\hline D8LS & 78 & 0.781 & 0.877 & 7.421 & 12.000 & 4.937 & 5.439 & 2.184 & 17488 \\
\hline D9LS & 72 & 1.073 & 0.831 & 4.622 & 7.183 & 3.840 & 4.001 & 2.151 & 26061 \\
\hline
\end{tabular}

Note. Mold temperature: $325^{\circ} \mathrm{C}$; ${ }^{*}$ large: angle of variable angle mold is $15^{\circ}$. 

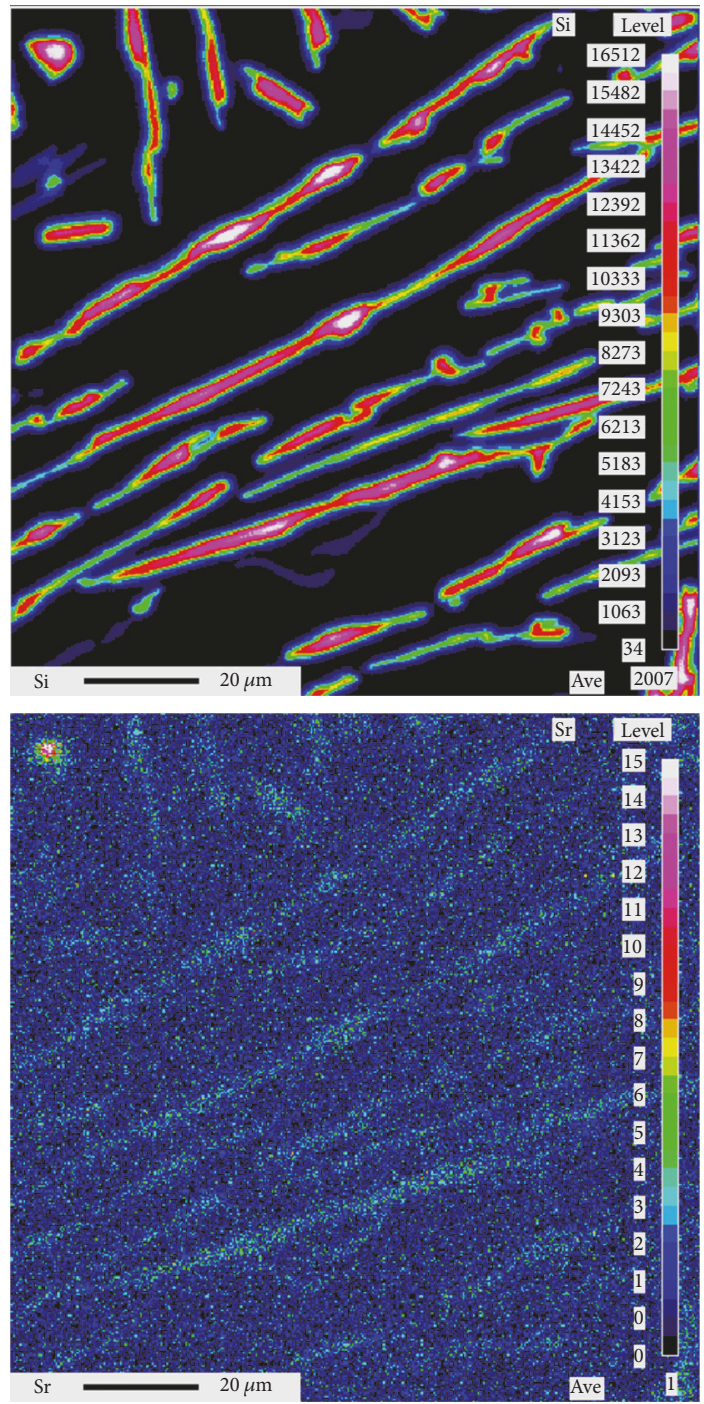

FIGURE 10: Distribution of Sr in the modified A356 alloy.

addition of RE exhibited a tendency for Si modification as may be seen from Table 4(b). As in the previous case (zero tilting angle), the standard deviation is also high in this case. It should be noted that $\mathrm{Ce}$ is relatively more effective than La as an alternate modification agent. Figures 9(a)-9(f) show examples of the eutectic Si morphology in A356 alloy samples treated with different amounts of RE, without (a, c, d) and with (b, e, f) Sr addition. It should be mentioned here that, according to the atomic radius ratio, $r_{\mathrm{La}} / r_{\mathrm{Si}}$ is 1.604 and $r_{\mathrm{Ce}} / r_{\mathrm{Si}}$ is 1.559 , which theoretically confirms the abovementioned observation [23].

Based on the data presented in Tables 4(a) and 4(b), the observed depression in the eutectic temperature is not necessarily related to modification of the eutectic Si particles. In confirmation of this conclusion, Table 4(c) lists the variation in the eutectic Si particles when the alloys were treated with $100 \mathrm{ppm} \mathrm{Sr}$. It is obvious that $\mathrm{Sr}$ is the most effective agent for modification compared to the other RE elements analyzed in the present study from both size and distribution aspects, as represented by the standard deviation. Figure 10 shows the distribution of Sr within the eutectic Si particles in the DBLS alloy. Figures 11 and 12 reveal the distribution of $\mathrm{La}, \mathrm{Ce}$, and $\mathrm{Sr}$ in RE-rich platelets, which explains the partial modification of the surrounding Si particles as less $\mathrm{Sr}$ is available for modification of the eutectic Si. It may be noted from Figures 9 and 10 that the affinity of La to react with $\mathrm{Sr}$ is relatively higher than that of $\mathrm{Ce}$.

3.2.2. Step-Like Mold. Since the modification effect of La is similar to that provided by $\mathrm{Ce}$, only $\mathrm{La}$ will be considered in this section. Table 5(a) lists the characteristics of the eutectic Si particles as a function of solidification rate and the level of La addition. Apparently, the solidification rate is the main factor affecting modification compared to the added La content. With the increase in the SDAS from $16 \mu \mathrm{m}$ to $41 \mu \mathrm{m}$, the average Si particle area increases from $3.7 \mu \mathrm{m}^{2}$ to $14 \mu \mathrm{m}^{2}$ with an increase in the La concentration to about 0.7 wt.\%. It should also be noted that the corresponding standard 
TABLE 5

(a) Silicon particle characteristics of La-containing A356 alloy samples obtained from step-like mold castings

\begin{tabular}{|c|c|c|c|c|c|c|c|c|c|}
\hline \multirow{3}{*}{ Alloy code } & \multirow{3}{*}{ Mold temp. $\left({ }^{\circ} \mathrm{C}\right)$} & \multirow{3}{*}{ Mold section } & \multirow{3}{*}{$\begin{array}{c}\text { RE addition } \\
\text { Actual } \\
\text { La (wt.\%) }\end{array}$} & \multicolumn{6}{|c|}{ Silicon particle characteristics } \\
\hline & & & & \multicolumn{2}{|c|}{ Area $\left(\mu \mathrm{m}^{2}\right)$} & \multicolumn{2}{|c|}{ Length $(\mu \mathrm{m})$} & \multirow{2}{*}{ Aspect ratio } & \multirow{2}{*}{ Density (number $/ \mathrm{mm}^{2}$ ) } \\
\hline & & & & Average & SD & Average & SD & & \\
\hline $12 S$ & \multirow{5}{*}{200} & \multirow{5}{*}{ Small (SDAS: $16 \mu \mathrm{m})$} & 0 & 3.663 & 5.680 & 3.444 & 3.567 & 2.272 & 13495 \\
\hline $22 \mathrm{~S}$ & & & 0.165 & 1.685 & 3.740 & 2.132 & 2.376 & 2.044 & 27050 \\
\hline $32 \mathrm{~S}$ & & & 0.356 & 1.364 & 3.825 & 1.898 & 2.229 & 2.029 & 38893 \\
\hline $42 \mathrm{~S}$ & & & 0.685 & 1.464 & 3.665 & 1.952 & 2.119 & 2.022 & 33243 \\
\hline $52 S$ & & & 1.025 & 1.506 & 4.175 & 1.879 & 2.306 & 1.978 & 35101 \\
\hline $12 \mathrm{~L}$ & \multirow{5}{*}{200} & \multirow{5}{*}{ Large (SDAS: $31 \mu \mathrm{m}$ ) } & 0 & 7.876 & 12.290 & 5.591 & 5.970 & 2.548 & 6471 \\
\hline $22 \mathrm{~L}$ & & & 0.165 & 6.763 & 11.410 & 4.743 & 5.394 & 2.230 & 7416 \\
\hline $32 \mathrm{~L}$ & & & 0.356 & 5.334 & 7.426 & 4.475 & 3.772 & 2.107 & 11179 \\
\hline $42 \mathrm{~L}$ & & & 0.685 & 5.194 & 10.910 & 4.318 & 4.639 & 2.162 & 6644 \\
\hline $52 \mathrm{~L}$ & & & 1.025 & 2.727 & 6.007 & 2.678 & 2.962 & 2.129 & 11145 \\
\hline $14 \mathrm{~S}$ & \multirow{5}{*}{400} & \multirow{5}{*}{ Small (SDAS: $22 \mu \mathrm{m})$} & 0 & 5.245 & 7.768 & 4.360 & 4.452 & 2.393 & 9361 \\
\hline $24 \mathrm{~S}$ & & & 0.165 & 3.371 & 4.856 & 3.148 & 2.908 & 2.147 & 13055 \\
\hline $34 \mathrm{~S}$ & & & 0.356 & 5.152 & 8.234 & 4.119 & 4.040 & 2.129 & 10819 \\
\hline $44 \mathrm{~S}$ & & & 0.685 & 4.517 & 7.080 & 3.671 & 3.844 & 2.092 & 13439 \\
\hline $54 \mathrm{~S}$ & & & 1.025 & 2.680 & 5.351 & 2.648 & 3.153 & 2.034 & 25475 \\
\hline $14 \mathrm{~L}$ & \multirow{5}{*}{400} & \multirow{5}{*}{ Large (SDAS: $41 \mu \mathrm{m}$ ) } & 0 & 15.800 & 24.850 & 8.113 & 9.591 & 2.565 & 3457 \\
\hline $24 \mathrm{~L}$ & & & 0.165 & 13.830 & 21.330 & 7.083 & 8.016 & 2.463 & 4007 \\
\hline $34 \mathrm{~L}$ & & & 0.356 & 15.160 & 24.430 & 7.668 & 9.044 & 2.385 & 3555 \\
\hline $44 \mathrm{~L}$ & & & 0.685 & 14.240 & 23.500 & 7.072 & 8.191 & 2.411 & 3788 \\
\hline $54 \mathrm{~L}$ & & & 1.025 & 9.514 & 16.030 & 5.746 & 6.027 & 2.363 & 5904 \\
\hline
\end{tabular}

Note. Small: sample sectioned from step of $5 \mathrm{~mm}$ height. Large: sample sectioned from step of $20 \mathrm{~mm}$ height. SD: standard deviation.

(b) Silicon particle characteristics of La-containing Sr-modified A356 alloy samples obtained from step-like mold castings

\begin{tabular}{|c|c|c|c|c|c|c|c|c|c|c|}
\hline \multirow{3}{*}{ Alloy code } & \multirow{3}{*}{ Mold temp. $\left({ }^{\circ} \mathrm{C}\right)$} & \multirow{3}{*}{ Mold section } & \multirow{2}{*}{\multicolumn{2}{|c|}{$\begin{array}{c}\text { Composition } \\
\text { Actual }\end{array}$}} & \multicolumn{6}{|c|}{ Silicon particle characteristics } \\
\hline & & & & & \multicolumn{2}{|c|}{ Area $\left(\mu \mathrm{m}^{2}\right)$} & \multicolumn{2}{|c|}{ Length $(\mu \mathrm{m})$} & \multirow{2}{*}{ Aspect ratio } & \multirow{2}{*}{ Density (number $/ \mathrm{mm}^{2}$ ) } \\
\hline & & & $\mathrm{Sr}(\mathrm{ppm})$ & La (wt.\%) & Average & $\mathrm{SD}$ & Average & $\mathrm{SD}$ & & \\
\hline S12S & \multirow{5}{*}{200} & \multirow{5}{*}{ Small } & 83.3 & 0 & 0.875 & 3.592 & 1.268 & 1.212 & 1.84 & 85236 \\
\hline S22S & & & 95.0 & 0.165 & 0.860 & 4.796 & 1.235 & 1.964 & 1.92 & 57253 \\
\hline S32S & & & 84.1 & 0.356 & 0.669 & 3.963 & 1.108 & 1.330 & 1.81 & 90306 \\
\hline S42S & & & 105.8 & 0.685 & 0.689 & 3.756 & 1.205 & 1.473 & 1.84 & 79410 \\
\hline S52S & & & 108.3 & 1.025 & 0.853 & 4.438 & 1.246 & 1.685 & 1.85 & 74495 \\
\hline S12L & \multirow{5}{*}{200} & \multirow{5}{*}{ Large } & 83.3 & 0 & 1.653 & 3.738 & 1.948 & 1.661 & 1.89 & 48426 \\
\hline S22L & & & 95.0 & 0.165 & 1.606 & 4.175 & 1.897 & 1.976 & 1.96 & 33046 \\
\hline S32L & & & 84.1 & 0.356 & 1.401 & 3.898 & 1.763 & 1.820 & 1.95 & 39323 \\
\hline S42L & & & 105.8 & 0.685 & 1.364 & 4.134 & 1.766 & 2.043 & 1.95 & 46551 \\
\hline S52L & & & 108.3 & 1.025 & 1.406 & 4.180 & 1.853 & 2.229 & 2.02 & 37318 \\
\hline S14S & \multirow{5}{*}{400} & \multirow{5}{*}{ Small } & 79.1 & 0 & 0.996 & 3.526 & 1.548 & 1.465 & 1.83 & 74841 \\
\hline S24S & & & 73.1 & 0.165 & 1.020 & 3.681 & 1.389 & 1.431 & 1.81 & 65911 \\
\hline S34S & & & 77.0 & 0.356 & 0.899 & 3.619 & 1.409 & 1.485 & 1.88 & 75695 \\
\hline S44S & & & 88.0 & 0.685 & 0.768 & 3.504 & 1.288 & 1.282 & 1.90 & 58987 \\
\hline S54S & & & 89.5 & 1.025 & 1.042 & 5.243 & 1.539 & 2.948 & 1.91 & 65816 \\
\hline S14L & \multirow{5}{*}{400} & \multirow{5}{*}{ Large } & 79.1 & 0 & 2.532 & 5.228 & 2.640 & 2.254 & 1.90 & 32512 \\
\hline S24L & & & 73.1 & 0.165 & 2.262 & 5.044 & 2.245 & 2.223 & 1.91 & 34871 \\
\hline S34L & & & 77.0 & 0.356 & 1.679 & 3.691 & 2.003 & 1.896 & 1.96 & 43197 \\
\hline S44L & & & 88.0 & 0.685 & 2.121 & 5.302 & 2.287 & 2.652 & 1.99 & 35591 \\
\hline S54L & & & 89.5 & 1.025 & 2.471 & 3.718 & 2.600 & 1.748 & 2.06 & 30309 \\
\hline
\end{tabular}

Note. Small: sample sectioned from step of $5 \mathrm{~mm}$ height. Large: sample sectioned from step of $20 \mathrm{~mm}$ height. SD: standard deviation. 


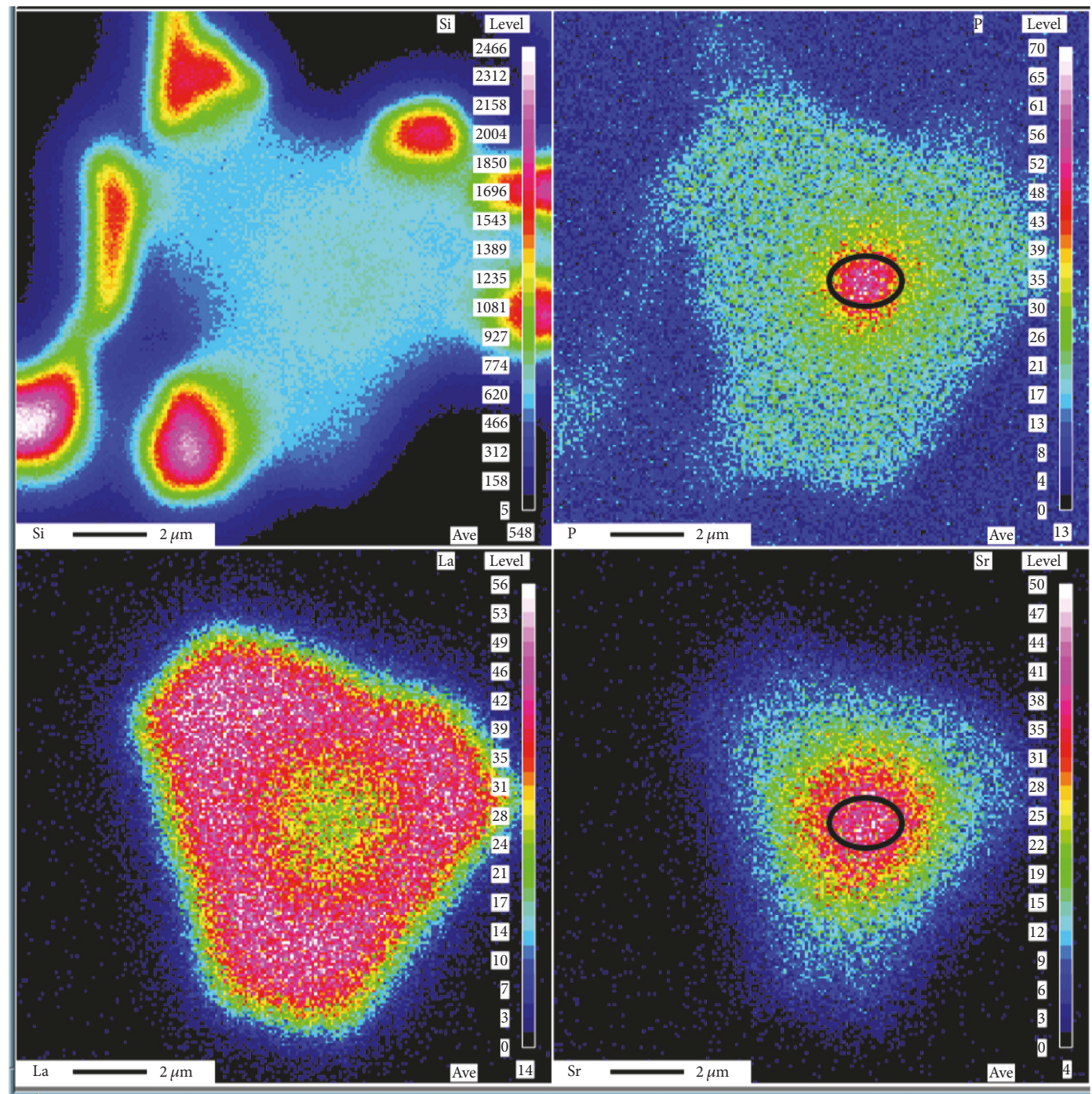

(a)

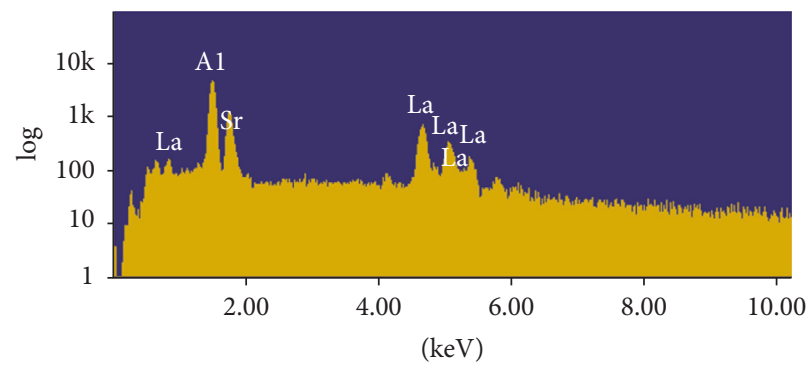

(b)

FIGURE 11: (a) Elemental distribution of Si, La, Sr, and P corresponding to a backscattered electron image showing La-rich platelet and surrounding Si particles in 100 ppm Sr-modified A356 alloy containing 1.025\% wt.\% La; (b) EDS spectrum of the La-rich platelet. Note the presence of $\mathrm{P}$ at the center of the $\mathrm{Sr}$ (circled areas).

deviation increased from \pm 5.7 to \pm 23.5 , indicating a wide range of Si particle sizes and distributions. At $\sim 1 \mathrm{wt} . \%$ La level, a tendency for modification is observed, as demonstrated by Figures 13(a) and 13(c). The variations in the Si particle characteristics in the same series of alloys with the addition of $\sim 100 \mathrm{ppm}$ Sr are shown in Table 5(b). The average Si particle area is about $1.5 \mu \mathrm{m}^{2} \pm 3.6$ regardless of the solidification rate and La concentration as displayed in Figures 13(b) and 13(d).

3.3. Porosity. Liao et al. [24] studied the effect of Sr addition on porosity formation in directionally solidified A356 alloy. Their results showed that the growth rate of pores decreases 


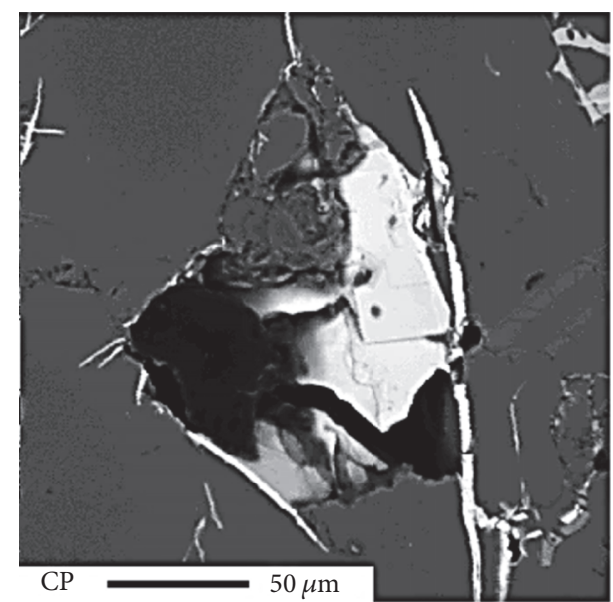

(a)

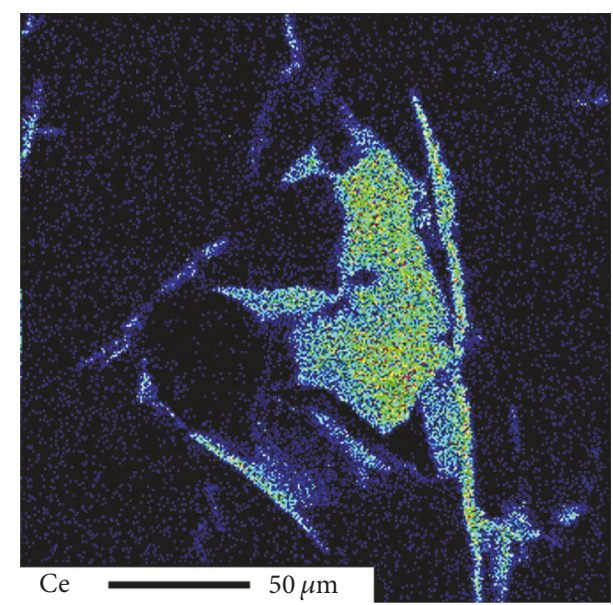

(b)

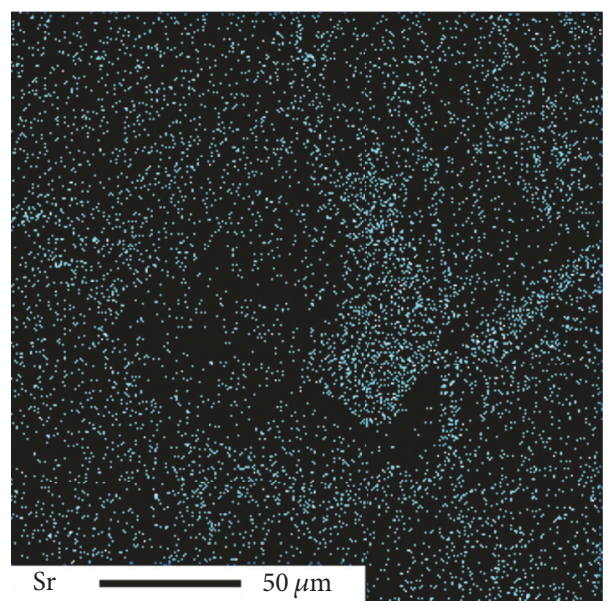

(c)

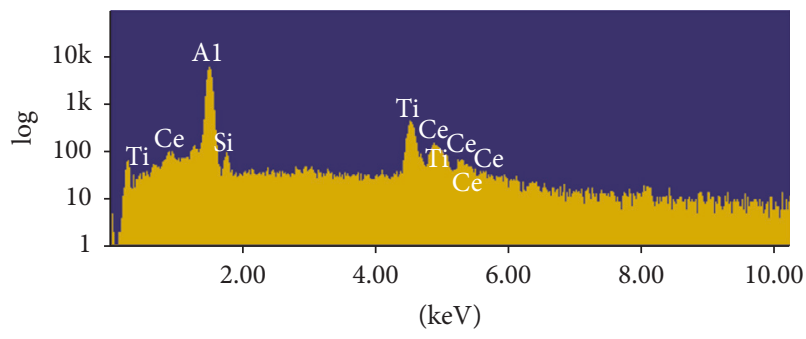

(d)

Figure 12: (a) Backscattered electron image showing Ce-rich platelets in Sr-modified A356 alloy containing 1.025\% wt.\% Ce and elemental distribution of (b) Ce, (c) Sr, and (d) EDS spectrum corresponding to (a).

with the reduction in local liquid temperature, while it fluctuates violently during directional solidification. Addition of $\mathrm{Sr}$ weakens this fluctuation and decreases the average growth rate of pores. Addition of Sr has a considerable influence on the size distribution of pores.

The modification of Al-Si casting alloys was analyzed by Sigworth [25]. Modification may change the relative formation of porosity and shrinkage in a casting. The modifiers strontium and sodium are poisoned by phosphorus, antimony, and bismuth. Consequently, the levels of these impurities should be monitored carefully in secondary alloys.

The effect of $\mathrm{Sr}$ content on porosity formation in a directionally solidified Al-12.3 wt.\% Si alloy was investigated by Hengcheng et al. [26] who suggested that Sr solute in liquid Al-Si alloys can diffuse into oxide inclusions to form loose oxide aggregations which are more active nucleation sites for porosity. Stunov [27] concluded that, in Al-Si-Mg alloys, $\mathrm{Sr}$ has a negative effect on the level of gas porosity and on the distribution of shrinkage porosity.

The effect of the metallurgical parameters on porosity formation examined in the present study was limited to the variable angle mold and the step-like mold. Figure 14 shows the general distribution of porosity in Sr-free degassed A356 alloy castings obtained from the variable angle mold heated at $350^{\circ} \mathrm{C}$, using different angles. As can be seen, the high solidification rate associated with the thin plates of the zerodegree angle castings may lead to the formation of hot spots within the casting as denoted by the black circled areas.

Figures 15(a) and 15(b) show two examples of the porosity observed in samples of Sr-modified A356 alloys containing La obtained from the $15^{\circ}$ variable angle mold. These pores are associated with thick oxide films (white arrows), as inferred 


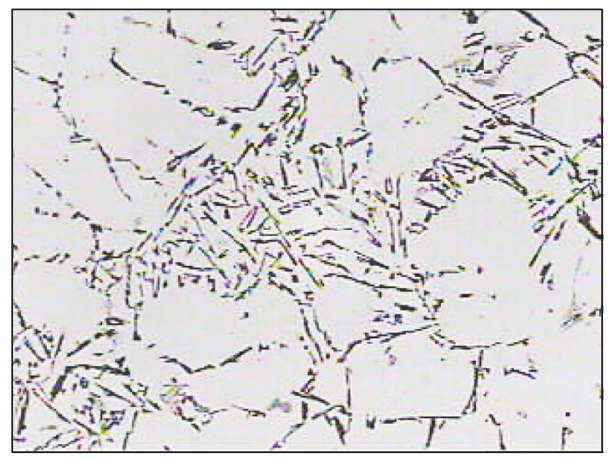

(a) No addition

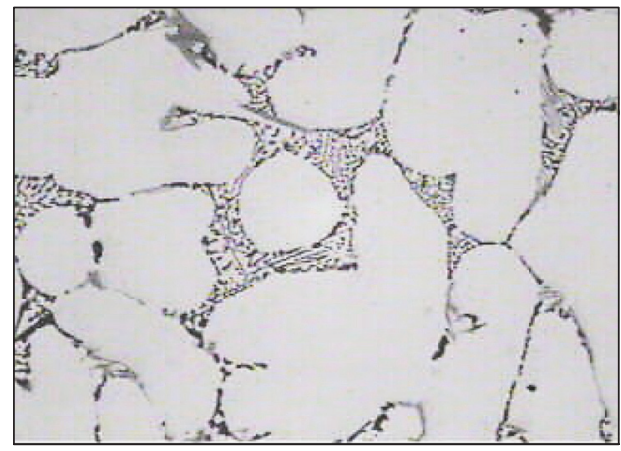

(c) After 1.025\% La addition

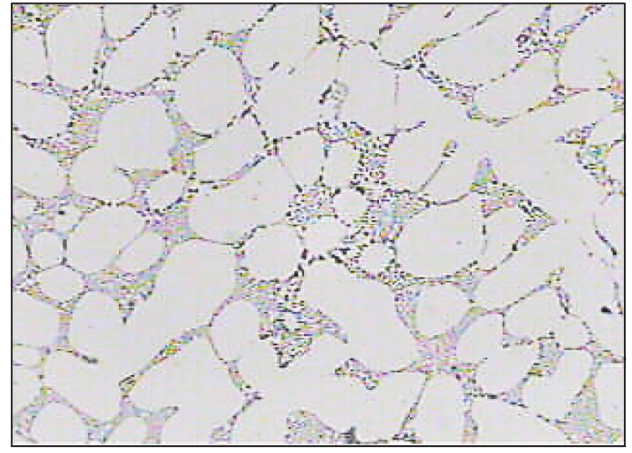

(b) After 100 ppm Sr addition

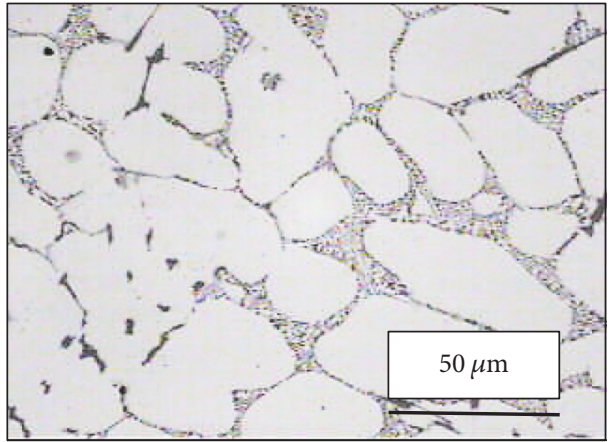

(d) After $\mathrm{La}+100 \mathrm{ppm}$ Sr addition

FIGURE 13: Examples of the eutectic Si particles observed in A356 alloy following addition of Sr, La, or Sr + La in samples obtained from the small section $\left(200^{\circ} \mathrm{C}\right)$ of the step-like mold casting.

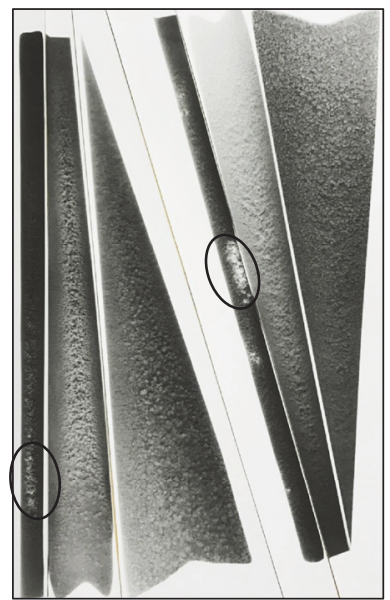

Figure 14: Porosity distribution in degassed A356 alloy castings obtained from the variable angle mold heated at $350^{\circ} \mathrm{C}$.

from the X-ray images of oxygen and strontium distribution corresponding to Figure 15(b), as shown in Figures 15(c) and 15(d). It should be kept in mind that these X-ray images were taken from deep pores. Thus, the distribution may have been affected by the pore morphology. Another important observation noted from Figure 15 is that the fragmentation of the La-rich platelets appears to occur in a similar manner to that reported for the fragmentation of $\beta-\mathrm{Al}_{5} \mathrm{FeSi}$ platelets [28].
Porosity measurements were carried out on nonmodified and Sr-modified La-containing A356 alloys as a function of La content, using samples obtained from the step-like mold castings. The obtained data is documented in Figure 16. Since the molten metal was properly degassed (humidity in the vicinity of the melt was about $13 \%$ ), the amount of dissolved hydrogen in the molten alloy would be at its threshold value. Thus, porosity in this case would be caused mainly by 


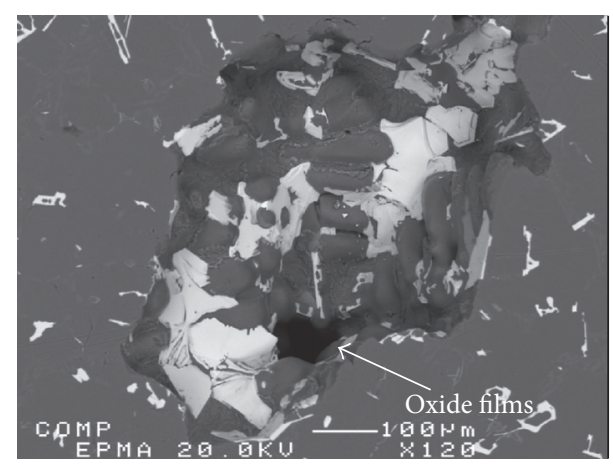

(a)

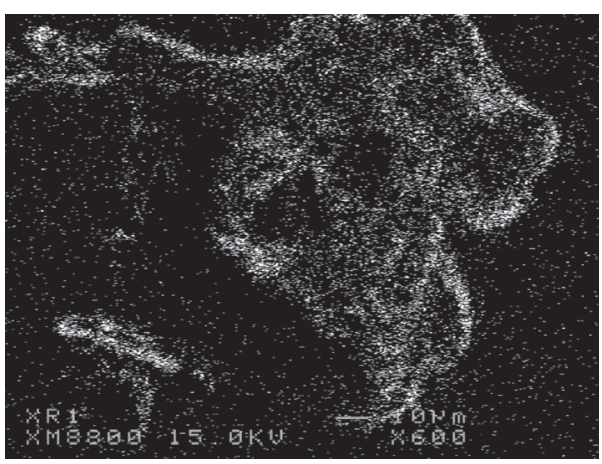

(c)

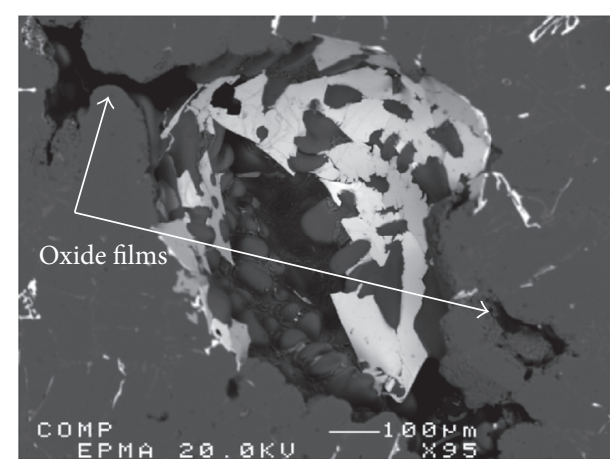

(b)

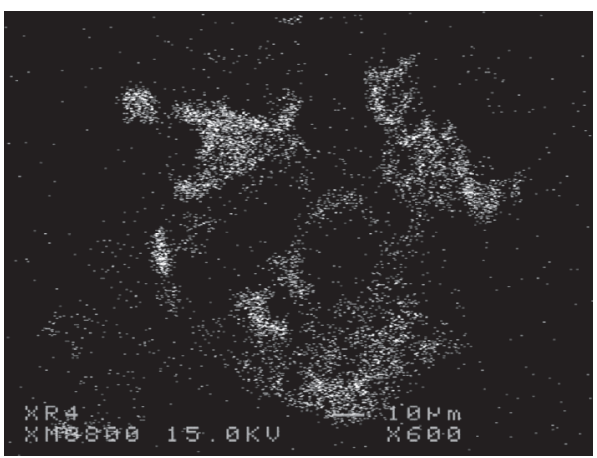

(d)

FiguRE 15: (a, b) Backscattered electron images showing porosity in Sr-modified A356 alloy samples containing (a) 0.8\% La and (b) 1.025\% La; note the presence of thick oxide films (white arrows) (sample SDAS $\sim 42 \mu \mathrm{m}$ ). (c, d) X-ray images showing the distribution of (c) oxygen and (d) strontium in (b).

shrinkage due to volumetric change during solidification. Liu et al. [29] reported that Sr oxide is one of the main sources of porosity due to the high affinity of Sr to react with oxygen. As was observed from Figure 5, the addition of RE resulted in an increase in the freezing range so that poor feedability of the molten metal would be expected.

Figure 16(a) presents the variation in percentage porosity as a function of solidification rate and the levels of $\mathrm{La}$ and $\mathrm{Sr}$ present in the alloy, where "Small" and "Large" correspond to samples obtained from the small and large steps of the steplike mold casting (see Figure 1(c)), and the suffixes 200 and 400 indicate the two temperatures of the mold during casting. In the absence of Sr, the total percentage porosity is less than $0.2 \%$ which decreases to $0.1 \%$ with the increase in the amount of La to 1.025 wt.\%.

With $100 \mathrm{ppm}$ Sr addition, a noticeable increase in the percentage porosity is observed, especially at low solidification rate (Figure 16(a)). It should be noted also that increasing the La content has no specific effect on percentage porosity. Figure 16(b) illustrates the increase in pore density (measured by number of pores $/ \mathrm{mm}^{2}$ ) emphasizing the strong role of modification with $\mathrm{Sr}$ coupled with low solidification rate in the intensity of porosity in the final casting [30].

Figure 17 shows an example of the shape and size of the type of porosity observed in a 1.025 wt.\% La-containing A356 alloy sample obtained from the large section of the step-like mold (mold heated at $400^{\circ} \mathrm{C}$ ). The La-based intermetallic phase is seen to precipitate in the form of platelets, surrounded by partially modified eutectic Si. The EDS spectrum corresponding to the La-containing platelet is shown in Figure 17(b) indicating that it is composed of $\mathrm{Al}$ and $\mathrm{La}$. The WDS analysis revealed that the composition of these platelets is $\mathrm{Al}_{3} \mathrm{La}$ (77.4 at.\% Al, 22.6 at.\% La). Figure 18 shows the fragmentation of a La-rich platelet under the same casting conditions.

\section{Conclusions}

Based on an analysis of the results obtained in this study, the following conclusions may be drawn:

(1) Addition of La and Ce rare earth (RE) metals leads to an increase in the $\alpha$-Al precipitation temperature, lowering at the same time the Al-Si eutectic temperature, resulting in long freezing temperature ranges and hence poor feedability.

(2) The changes in both $\alpha$-Al and Si eutectic temperatures are independent of the undercooling.

(3) Addition of Sr to RE-treated alloys eliminates their effect on the microstructure during solidification. 


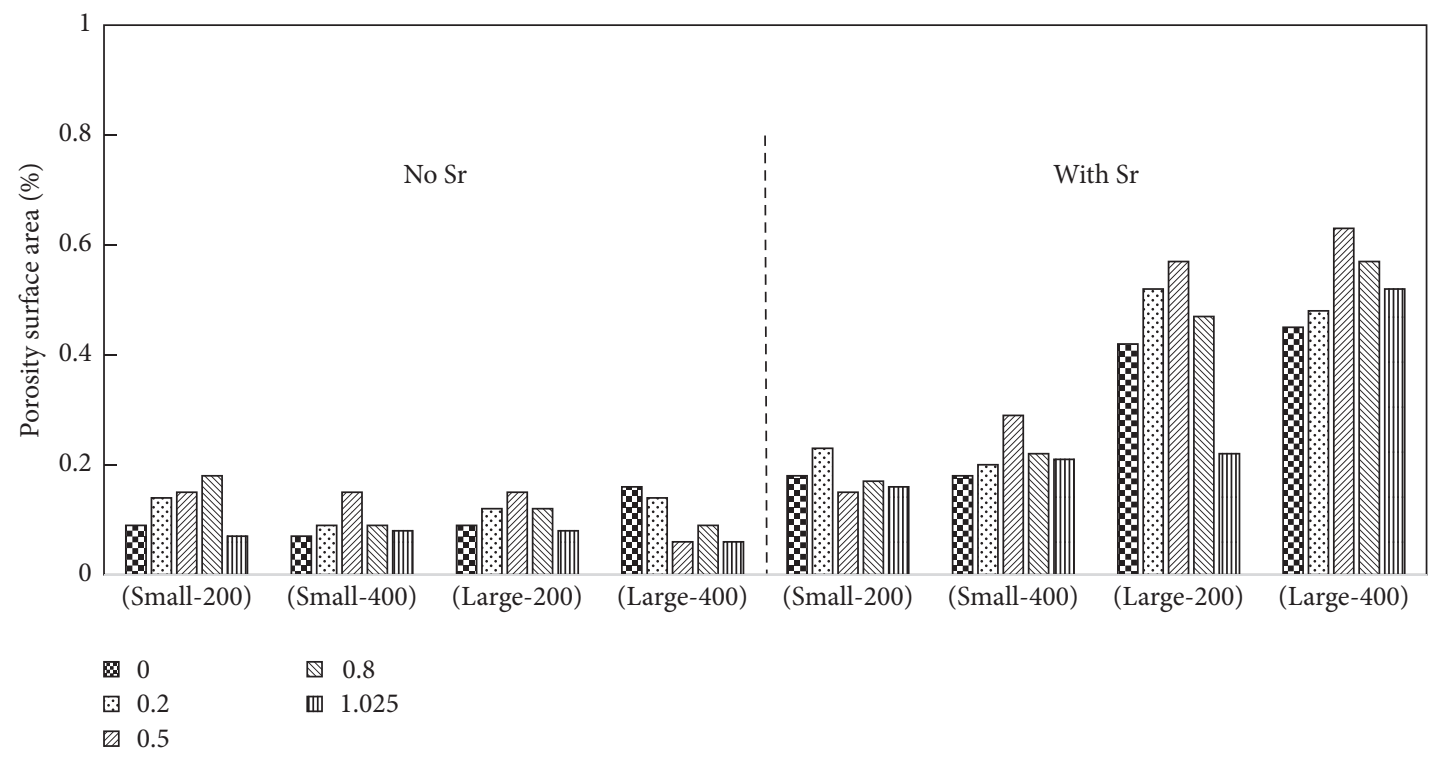

(a) Variation in surface area percentage porosity as a function of La content and casting/solidification condition of the A356 alloy samples (legend at the top center indicates the La level of the samples)

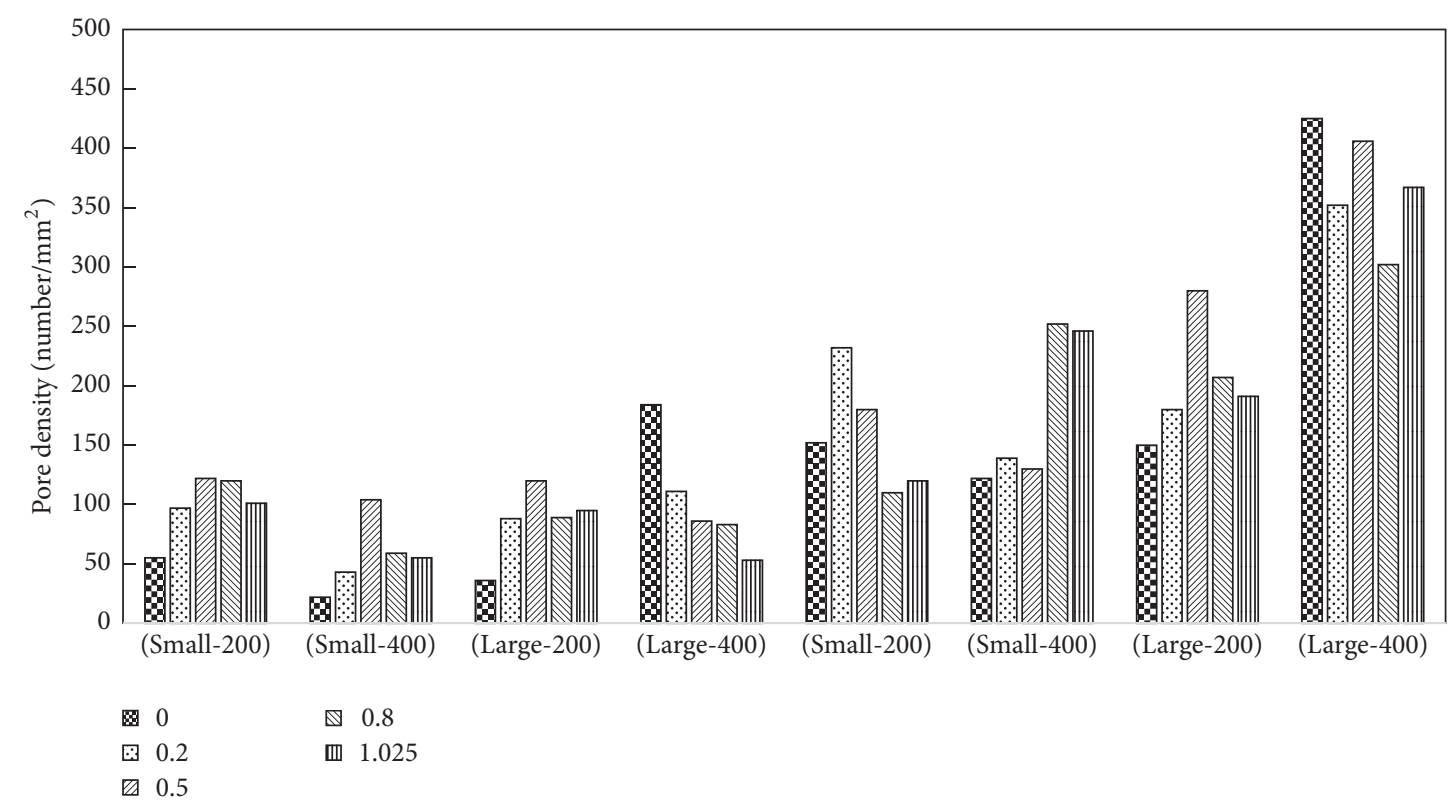

(b) Variation in pore density as a function of La content and casting/solidification condition of the A356 alloy samples (legend at the top center indicates the La level of the samples)

FIGURE 16

(4) Rare earth metals have a minor effect on the refinement of the eutectic silicon particles whereas $\mathrm{Sr}$ is the dominating modifying agent.

(5) According to the atomic radius ratio, $r_{\mathrm{La}} / r_{\mathrm{Si}}$ is 1.604 and $r_{\mathrm{Ce}} / r_{\mathrm{Si}}$ is 1.559 , theoretically, which shows Ce to be a more effective modifier than La.

(6) Strontium has a strong affinity for reacting with rare earth metals, which results in reducing its effectiveness as a eutectic Si modifier.
(7) The presence of traces of P observed in the A356 alloy samples leads to a reaction between $\mathrm{P}$ and $\mathrm{Sr}$ in the Sr-modified alloys, forming a complex compound which acts as a nucleation site for the precipitation of RE-rich phases.

(8) Porosity occurs mainly due to shrinkage and oxide films. In the absence of Sr, addition of rare earth metals, especially at high concentration, reduces the percentage of shrinkage porosity. 


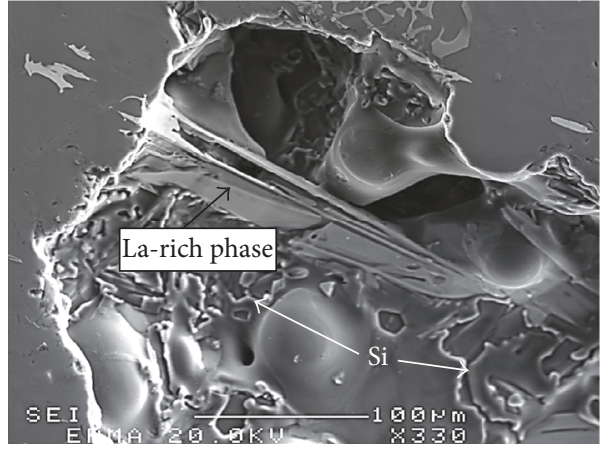

(a)

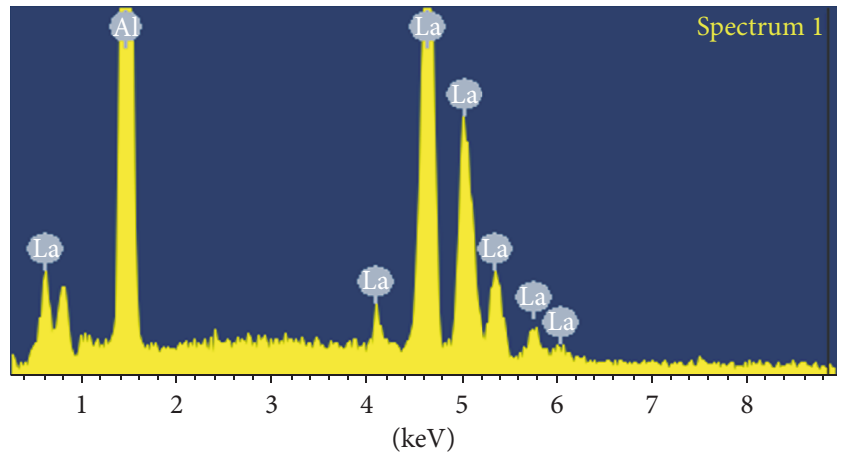

Full-scale 456 cts. cursor: 8.867 (13 cts.)

(b)

FIGURE 17: (a) Secondary electron image showing porosity in A356 alloy containing 1.025 wt.\% La and no Sr (sample SDAS 42 $\mu \mathrm{m}$ ). (b) EDS spectrum corresponding to the La-rich phase platelet (black arrow) in (a).

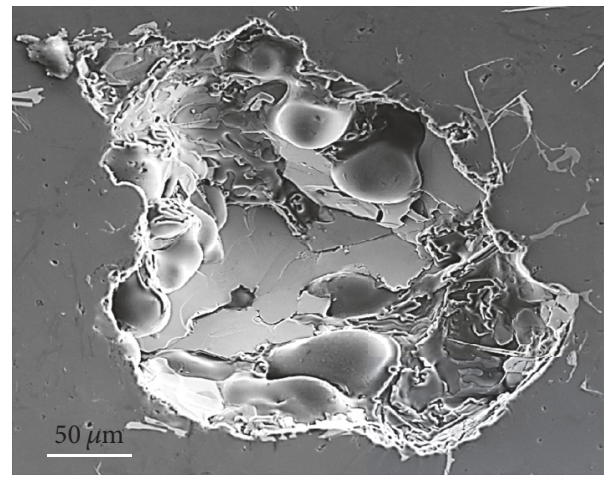

FIGURE 18: Secondary electron image of La-rich platelet within a pore in Sr-modified, high (1.025\%) La-containing A356 alloy (sample SDAS $\sim 42 \mu \mathrm{m})$.

(9) Addition of $\mathrm{Sr}$ causes fragmentation of the rare earth intermetallics similar to that observed for the $\beta$ $\mathrm{Al}_{5} \mathrm{FeSi}$ iron intermetallic phase.

\section{Conflicts of Interest}

The authors declare that they have no conflicts of interest.

\section{Acknowledgments}

The authors would like to thank Amal Samuel and Hicham Farid for enhancing the quality of the images and figures presented in this article.

\section{References}

[1] R. Sharan and N. P. Saksena, "Rare earth additions as modifiers of aluminum silicon alloys," AFS International Cast Metals Journal, vol. 3, no. 1, pp. 29-33, 1978.

[2] Y.-C. Tsai, C.-Y. Chou, R.-R. Jeng, S.-L. Lee, and C.-K. Lin, "Effect of rare earth elements addition on microstructures and mechanical properties of A356 alloy," International Journal of Cast Metals Research, vol. 24, no. 2, pp. 83-87, 2011.
[3] A. M. A. A Mohamed, A. M. Samuel, F. H. Samuel, and A. M. A. Al-Ahmari, "Effects of rare earths on the As-Cast Microstructure of an Al-Si-Mg alloy," AFS Transactions, vol. 119, pp. 83-91, 2011.

[4] A. Saoudi, F. H. Samuel, A. M. Samuel, and H. W. Doty, "Influence of the addition of rare earth metals and of overheating on microstructure and mechanical properties of aluminium alloy A319," Revue de Metallurgie. Cahiers D'Informations Techniques, vol. 100, no. 12, pp. 1203-1212, 2003.

[5] C. B. Kim and R. W. Heine, "Fundamentals of modification in the aluminum-silicon system," Journal of the Institute of Metals, vol. 92, pp. 367-376, 1963-1964.

[6] E. Aguirre-De la Torre, R. Pérez-Bustamante, J. CamarilloCisneros, C. D. Gómez-Esparza, H. M. Medrano-Prieto, and R. Martínez-Sánchez, "Mechanical properties of the A356 aluminum alloy modified with La/Ce," Journal of Rare Earths, vol. 31, no. 8, pp. 811-816, 2013.

[7] K. Nogita, S. D. McDonald, and A. K. Dahle, "Eutectic modification of Al-Si alloys with rare earth metals," Materials Transactions, vol. 45, no. 2, pp. 323-326, 2004.

[8] Z.-W. Chen, X.-L. Hao, J. Zhao, and C.-Y. Ma, "Kinetic nucleation of primary $\alpha(\mathrm{Al})$ dendrites in $\mathrm{Al}-7 \% \mathrm{Si}-\mathrm{Mg}$ cast alloys with Ce and Sr additions," Transactions of Nonferrous Metals Society of China, vol. 23, no. 12, pp. 3561-3567, 2013. 
[9] S. A. Alkahtani, E. M. Elgallad, M. M. Tash, A. M. Samuel, and F. H. Samuel, "Effect of rare earth metals on the microstructure of Al-Si based alloys," Materials, vol. 9, no. 1, article 45, 2016.

[10] O. El Sebaie, A. M. Samuel, F. H. Samuel, and H. W. Doty, "The effects of mischmetal, cooling rate and heat treatment on the eutectic Si particle characteristics of A319.1, A356.2 and A413.1 Al-Si casting alloys," Materials Science and Engineering A, vol. 480, no. 1-2, pp. 342-355, 2008.

[11] O. Elsebaie, F. H. Samuel, and S. Al Kahtani, "Intermetallic phases observed in nonmodified and $\mathrm{Sr}$ modified Al-Si cast alloys containing mischmetal," International Journal of Cast Metals Research, vol. 26, no. 1, pp. 1-15, 2013.

[12] G. H. Garza-Elizondo, A. M. Samuel, S. Valtierra, and F. H. Samuel, "Effect of $\mathrm{Ni}, \mathrm{Mn}, \mathrm{Sc}$, and $\mathrm{Zr}$ addition on the tensile properties of 354-type alloys at ambient temperature," International Journal of Metalcasting, vol. 11, no. 3, pp. 396-412, 2017.

[13] R. Aparicio, G. Barrera, G. Trapaga, M. Ramirez-Argaez, and C. Gonzalez-Rivera, "Solidification kinetics of a near eutectic Al-Si alloy, unmodified and modified with Sr," Metals and Materials International, vol. 19, no. 4, pp. 707-715, 2013.

[14] L. Hengcheng, B. Juanjuan, Z. Min, D. Ke, J. Yunfeng, and C. Mingdong, "Effect of strontium and solidification rate on eutectic grain structure in an Al-13 wt\% Si alloy," China Foundry, vol. 6, no. 3, pp. 226-231, 2009.

[15] K. Nogita, J. Drennan, and A. K. Dahle, "Evaluation of silicon twinning in hypo-eutectic Al-Si alloys," Materials Transactions, vol. 44, no. 4, pp. 625-628, 2003.

[16] D. Ferdian, J. Lacaze, I. Lizarralde, A. Niklas, and A. I. Fernández-Calvo, "Study of the effect of cooling rate on eutectic modification in A356 aluminium alloys," Materials Science Forum, vol. 765, pp. 130-134, 2013.

[17] L. F. Mondolfo, Aluminum Alloys, Structure and Properties, Butterworth, London, England, 1979.

[18] A. M. Samuel, G. H. Garza-Elizondo, H. W. Doty, and F. H. Samuel, "Role of modification and melt thermal treatment processes on the microstructure and tensile properties of $\mathrm{Al}-\mathrm{Si}$ alloys," Materials and Design, vol. 80, pp. 99-108, 2015.

[19] A. M. Samuel, H. W. Doty, S. Valtierra, and F. H. Samuel, "Effect of $\mathrm{Mg}$ addition of microstructure of 319 type alloys," International Journal of Cast Metals Research, vol. 26, no. 6, pp. 354363, 2013.

[20] A. Reis, Z. A. Xu, R. V. Toi et al., "Model for prediction of shrinkage defects in long and short freezing range materials," International Journal of Cast Metals Research, vol. 20, no. 3, pp. 171-175, 2007.

[21] S. Hegde and K. N. Prabhu, "Modification of eutectic silicon in Al-Si alloys," Journal of Materials Science, vol. 43, no. 9, pp. 3009-3027, 2008.

[22] E. Ogris, A. Wahlen, H. Lüchinger, and P. J. Uggowitzer, "On the silicon spheroidization in Al-Si alloys," Journal of Light Metals, vol. 2, no. 4, pp. 263-269, 2002.

[23] H. Qiu, H. Yan, and Z. Hu, "Modification of near-eutectic Al-Si alloys with rare earth element samarium," Journal of Materials Research, vol. 29, no. 11, pp. 1270-1277, 2014.

[24] H. C. Liao, W. Song, Q. G. Wang, L. Zhao, R. Fan, and F. Jia, "Effect of $\mathrm{Sr}$ addition on porosity formation in directionally solidified A356 alloy," International Journal of Cast Metals Research, vol. 26, no. 4, pp. 201-208, 2013.

[25] G. K. Sigworth, "The modification of Al-Si alloys: Important practical and theoretical aspects," International Journal of Metalcasting, vol. 2, no. 2, pp. 19-40, 2008.
[26] L. Hengcheng, W. Yuna, F. Ran, and W. Qigui, "Effect of Sr content on porosity formation in directionally solidified Al12.3wt.\%Si alloy," China Foundry, vol. 11, pp. 435-439, 2014.

[27] B. B. Stunov, "Strontium as a Structure Modifier for Non-binary AlSi Alloy," ActaPolytechnica, vol. 52, pp. 26-32, 2012.

[28] A. M. Samuel, H. W. Doty, S. Valtierra, and F. H. Samuel, "Metallographic Studies on the Intermetallic Phases in the Al-Si Near Eutectic and Eutectic Alloys," in Proceedings of the 120th AFS Metalcasting Congress, 12 pages, Minneapolis, Minn, USA, April 2016, Paper 16-095.

[29] L. Liu, A. M. Samuel, F. H. Samuel, H. W. Doty, and S. Valtierra, "Influence of oxides on porosity formation in Sr-treated Al-Si casting alloys," Journal of Materials Science, vol. 38, no. 6, pp. 1255-1267, 2003.

[30] Z. Ma, A. M. Samuel, F. H. Samuel, and H. W. Doty, "Effect of Fe content and cooling rate on the impact toughness of cast 319 and 356 aluminum alloys," AFS Transactions, vol. 111, pp. 255265, 2003.

[31] L. Bäckerud, G. Chai, and J. Tamminen, Solidification Characteristics of Aluminum Alloys, Vol. 2: Foundry Alloys, vol. 2, AFS/Skanaluminium, Des Plaines, Illinois, USA, 1990. 

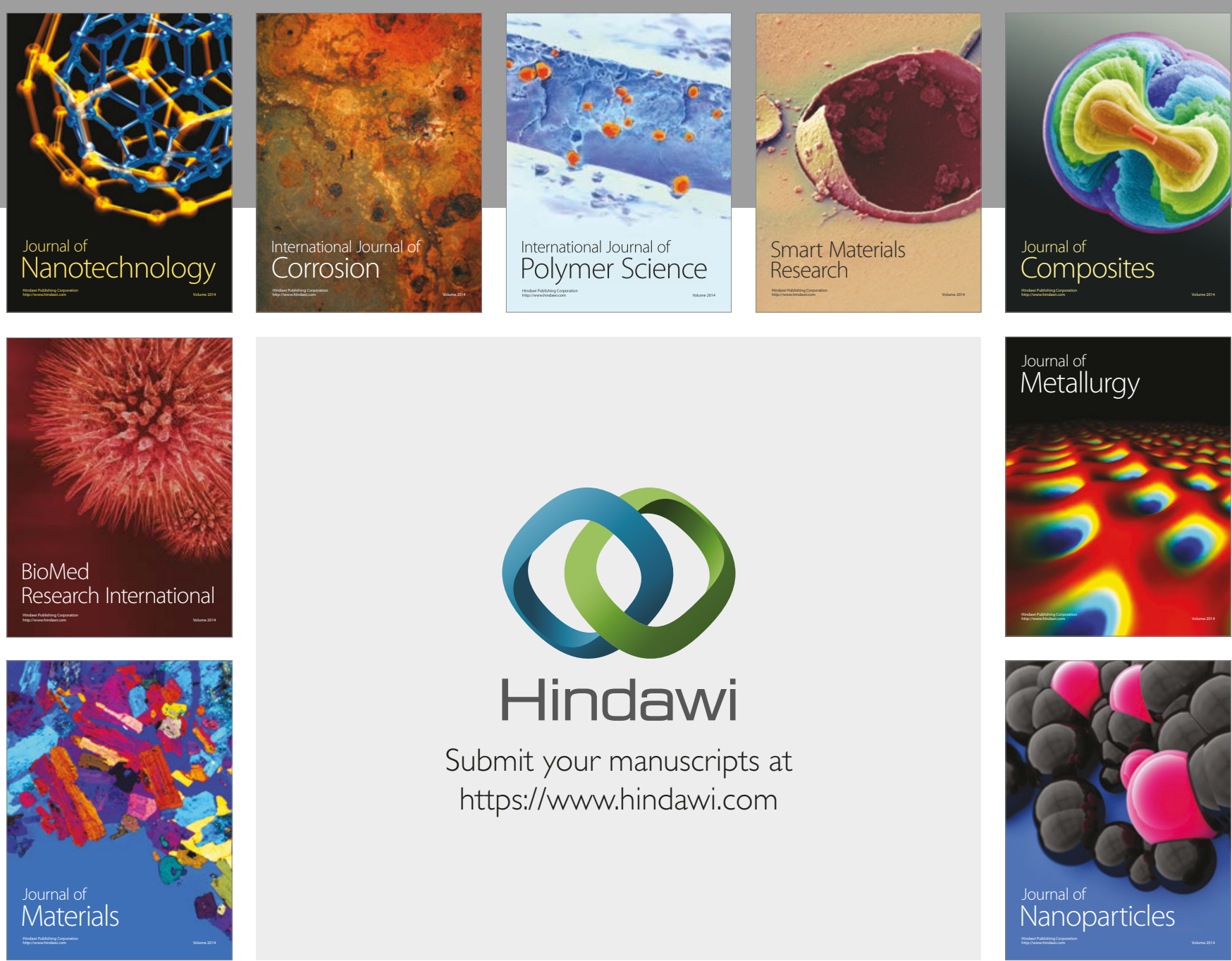

\section{Hindawi}

Submit your manuscripts at

https://www.hindawi.com
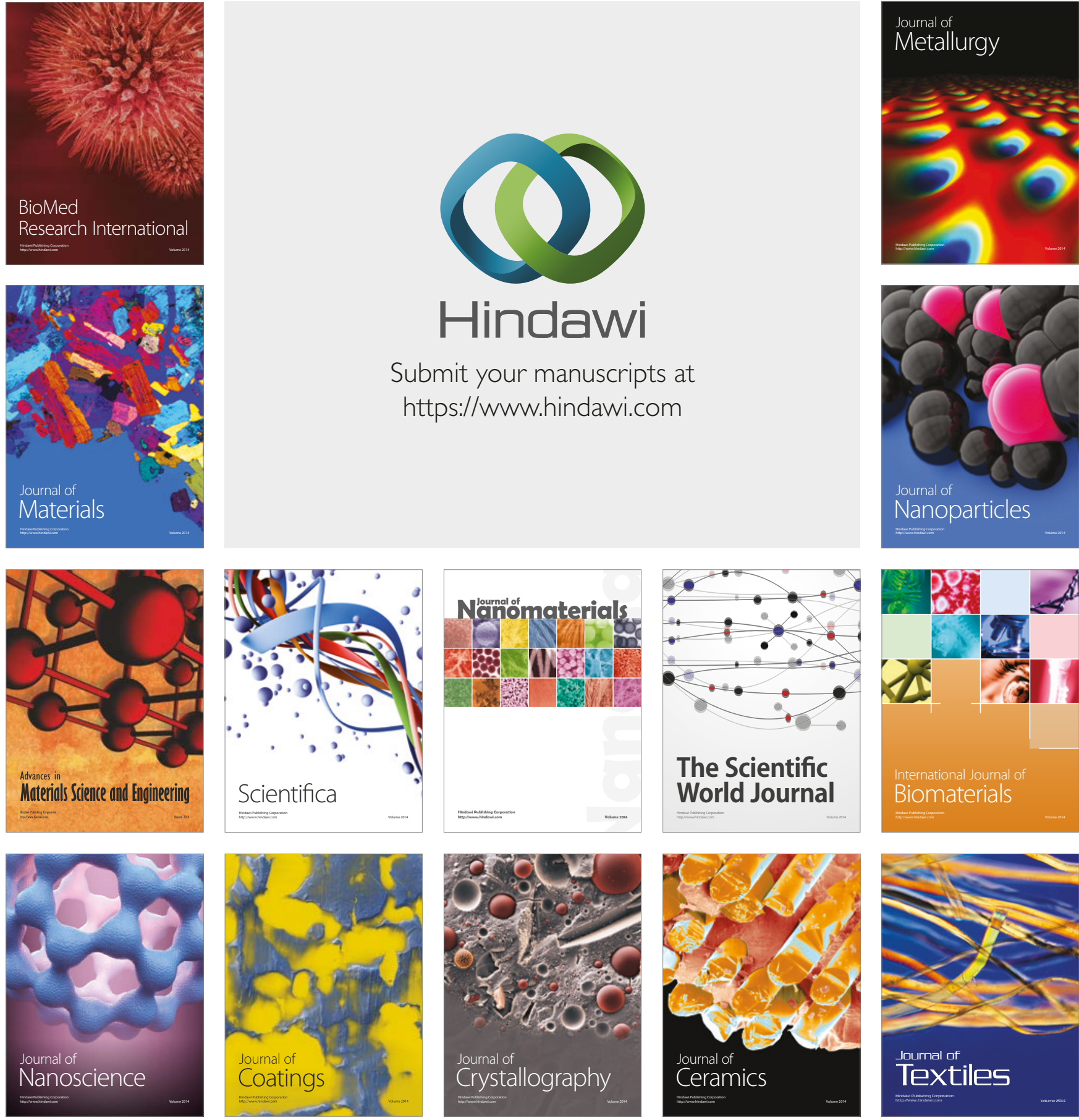

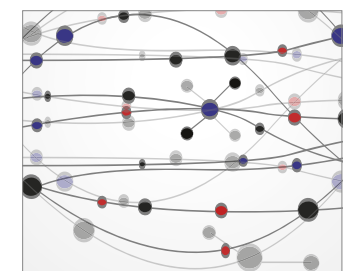

The Scientific World Journal
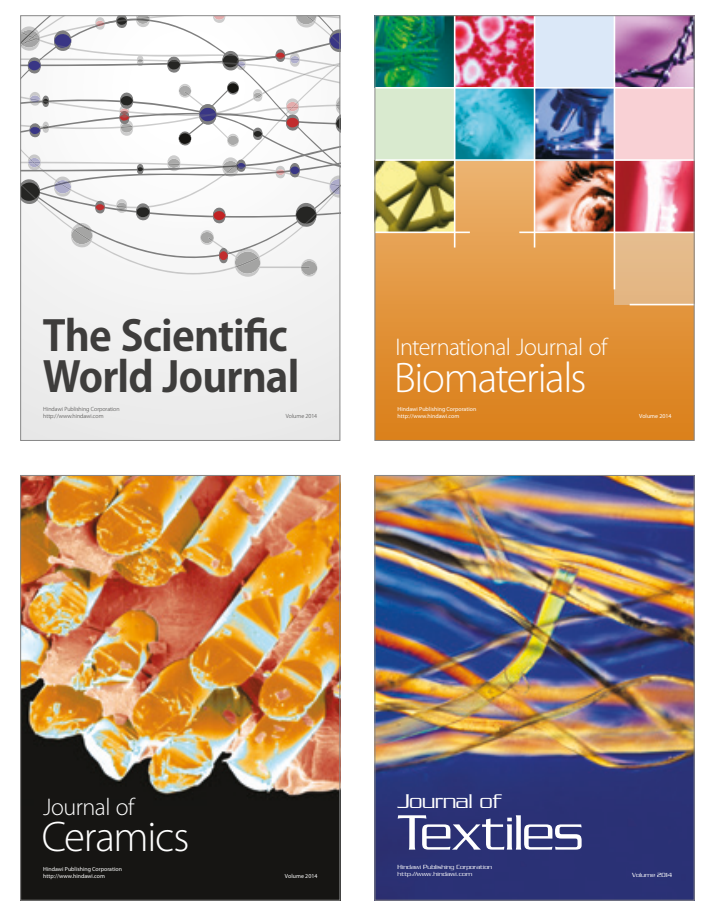